\title{
EL DELITO DE VIOLACIÓN EN EL CÓDIGO PENAL ESPAÑOL: ANÁLISIS DE LA DIFÍCIL DELIMITACIÓN ENTRE LA INTIMIDACIÓN DE LA AGRESIÓN SEXUAL Y EL PREVALIMIENTO DEL ABUSO SEXUAL. REVISIÓN A LA LUZ DE LA NORMATIVA INTERNACIONAL
}

The crime of rape in the Spanish Criminal Code: analysis of the difficult delimitation between intimidation of sexual assaul and "prevalimiento» of sexual abuse. A revision in the light of the international regulations

\author{
Itziar Altuzarra Alonso \\ Universidad de Deusto \\ itziar.altuzarra@opendeusto.es
}

http://dx.doi.org/10.18543/ed-68(1)-2020pp511-558

Recibido: 05.02.2020

Aceptado: 08.06.2020

\section{Resumen}

Caracterizado por un alto porcentaje de victimización de la mujer, el delito de violación se trata de uno de los crímenes sexuales históricamente más sancionados. Su regulación, tanto a nivel internacional como nacional, sigue en constante evolución, pues se trata de una conducta típica profundamente relacionada con el progresivo proceso de concienciación sobre la deconstrucción del sistema patriarcal que impacta profundamente en la sensibilidad social colectiva. El objetivo principal del trabajo consiste en arrojar luz al amplísimo debate doctrinal y jurisprudencial generado en torno a la consideración de la violencia y la intimidación como elementos definitorios de este delito. En esta línea, el Código penal español exige la concurrencia uno de dichos medios comisivos para llegar a denominar como violación al 
ataque a la libertad sexual con acceso carnal, lo que supone la creación de una línea divisoria muy sutil entre la violación intimidatoria y el abuso sexual por prevalimiento. Dicha regulación no se adecúa a los estándares legales internacionales, y concretamente europeos, que España ha ratificado hace ya cinco años a través del Convenio de Estambul. Por ello, se concluye que la legislación nacional, a pesar de haber experimentado una intensa metamorfosis, todavía hoy en día precisa una revisión y reformulación del crimen de violación dirigida hacia su consideración en torno a la falta de consentimiento de la víctima como elemento definitorio. Finalmente, se colige además que en el enjuiciamiento de dicho crimen urge una formación en perspectiva de género dirigida a jueces y magistrados cuyas motivaciones jurídicas, se observa, tienen un poder decisivo.

\section{Palabras clave}

Derecho penal; Violencia sexual; Delitos sexuales; Libertad sexual; Violación; Consentimiento; Género.

\section{Abstract}

Characterized by a high percentage of victimization of women, the crime of rape is historically one of the most sanctioned sex crimes. Its regulation, both at an international and national level, keeps on evolving since it is a criminal behaviour deeply related to the progressive process of awareness about the deconstruction of the patriarchal system that greatly impacts on the collective social sensitivity. The main aim of the work consists on shedding light on the doctrinal and jurisprudential broad debate generated around the consideration of violence and intimidation as defining elements of the crime. In this line, the Spanish Criminal Code requires one of both methods in which to commit the crime to consider that any attack against sexual freedom including sexual intercourse constitutes rape, what implies the creation of a dividing, though extremely subtle, line between rape through intimidation and sexual abuse through prevalimiento. This regulation is not conformed to the international legal standards, and specifically European, that Spain ratified five years ago by virtue of the Istanbul Convention. In consequence, it can be concluded that the national legislation, despite having experienced an intense metamorphosis, is still in need of a review and reformulation of the crime of rape aimed to its consideration around the absence of consent of the victim as the only defining element. Finally, it is also deduced that the prosecution of the mentioned crime urges the implementation of a gender perspective training addressed to judges and magistrates whose legal motivations have decisive power.

\section{Keywords}

Criminal law; Sexual violence; Sex crimes; Sexual freedom; Rape; Consent; Gender. 


\begin{abstract}
SUMARIO: I. INTRODUCCIÓN. II. ViOLENCIA SEXUAL Y VIOLACIÓN: REGULACIÓN INTERNACIONAL. 1. Desarrollo en el derecho penal internacional. 2. Marco legal en Europa. III. LA VIOLACIÓN EN EL CóDiGo PENAL ESPAÑOL Y SUS LÍMITES CON EL ABUSO SEXUAL. 1. Desde la honestidad de la mujer hasta la libertad sexual de todos y todas. 2. Una primera aproximación y la violencia en la agresión sexual. 3. La agresión sexual intimidatoria con acceso carnal y el abuso sexual con prevalimiento con acceso carnal: problemas de distinción. 3.1. La intimidación en las agresiones sexuales con acceso carnal. 3.2. El prevalimiento en los abusos sexuales con acceso carnal. 3.3. «Una sutil línea divisoria». IV. VALORACIONES CRÍTICAS: REVISIÓN DEL CÓDIGO PENAL EN RAZÓN DE SUS DISFUNCIONALIDADES Y A LA LUZ DE LA NORMATIVA INTERnACIONAL. V. Conclusiones. VI. Fuentes. VII. AneXOS.
\end{abstract}

\title{
I. INTRODUCCIÓN
}

No existe una legislación unánime a nivel comparado en torno a la violencia sexual, pues los sistemas penales nacionales recogen diferentes delitos sexuales con distintas definiciones y sanciones para los mismos. Sin embargo, generalmente esta violencia se relaciona con los delitos de violación, abuso sexual, acoso sexual, trata de personas y prostitución, entre otros, y muchos países han ratificado estándares internacionales que abordan la problemática. Así, la OMS define la violencia sexual como

«todo acto sexual, la tentativa de consumar un acto sexual, los comentarios o insinuaciones sexuales no deseados, o las acciones para comercializar o utilizar de cualquier otro modo la sexualidad de una persona mediante coacción por otra persona, independientemente de la relación de esta con la víctima, en cualquier ámbito», y continua, «también puede ocurrir cuando la persona agredida no está en condiciones de dar su consentimiento» ${ }^{1}$.

El presente trabajo contempla a la mujer como principal víctima de la violencia sexual. Este hecho responde a los datos recabados en diferentes estudios ${ }^{2}$ que

${ }^{1}$ Organización Mundial de la Salud. Informe mundial sobre la violencia y la salud, Washington, D.C.: Oficina Regional para las Américas, 2003, p. 161. Explica también que la coacción «además de la fuerza física, puede entrañar la intimidación psíquica, la extorsión u otras amenazas»».

2 Agencia de los Derechos Fundamentales de la UE, Violence Against Women: an EU-wide survey. Main Results, Luxemburgo, 2014, p. 7 disponible en https://fra.europa. $\mathrm{eu} /$ sites/default/files/fra_uploads/fra-2014-vaw-survey-main-results-apr14_en.pdf y Naciones Unidas. The Special Rapporteur on Violence against Women, $1 \overline{5}$ years of the United Nations Special Rapporteur on Violence Against Women, Its Causes and Conse- 
ponen de manifiesto el sesgo de género que caracteriza esta violencia, afectando masivamente a las mujeres. Así, a nivel estatal, el $84 \%$ de las víctimas de delitos contra la libertad sexual en España son mujeres, mientras que sólo el 16\% son hombres ${ }^{3}$. Además, el $96 \%$ de detenidos e investigados por estos delitos son hombres y sólo el $4 \%$ son mujeres ${ }^{4}$. Respecto al ámbito europeo, el $11 \%$ de las mujeres mayores de 15 años en la UE han experimentado alguna forma de violencia sexual y el $5 \%$ han sido violadas ${ }^{5}$, se observa también que la violencia sexual es masivamente ejecutada por hombres ${ }^{6}$. Sin embargo, esta problemática no está circunscrita a regiones o culturas específicas, pues se estima que 15 millones de mujeres de entre 15 y 19 años en todo el mundo han sido obligadas a mantener relaciones sexuales al menos una vez en su vida ${ }^{7}$. Por todo esto se concluye que, a pesar de no ser las únicas, las mujeres son las principales víctimas de esta de violencia que se presenta en todo el mundo.

De este modo, los estándares legales internacionales en torno a la violencia sexual se han configurado dentro del marco de la violencia de género ${ }^{8} \mathrm{y}$

quences, 2009, p 16. Cabe destacar que debido a la ausencia de denuncia de muchos incidentes y a la ineficiencia de algunos sistemas de justicia penales, existe una gran dificultad para obtener datos completos, lo que lleva a que se ofrezca una visión parcial de la realidad mientras otra parte de los comportamientos delictivos queda oculta e impune.

3 Además, el porcentaje de victimización de la mujer aumenta en el caso de los abusos ( $\sin$ acceso carnal un $86 \%$ y con acceso carnal un 93\%) y las agresiones sexuales (sin acceso un $92 \%$ y con acceso carnal un $93 \%$ ). Ministerio del Interior. Informe sobre delitos contra la libertad e indemnidad sexual en España, Gabinete de Coordinación y Estudios, Secretaría de Estado de Seguridad, 2017, p. 15.

4 Ibídem, p. 27.

5 Agencia de los Derechos Fundamentales de la UE, Violence Against Women...op. cit., p. 3 y 21. La Agencia lleva a cabo un representativo estudio en el que entrevista a 42.000 mujeres de 28 países de la UE.

${ }^{6}$ Ibídem, p. 7.

7 UNICEF, A familiar face: violence in the life of children and adolescents. Nueva York, 2017, p. 75 disponible en https://www.unicef.org/publications/files/Violence_in the lives_of_children_and_adolescents.pdf y Organización Mundial de la Salud, Informe mundial... op . cit, p. 161

${ }^{8}$ El concepto «género», que ha sido asumido por la sociología y la filosofía jurídica, se atribuye al movimiento feminista que distingue así el sexo biológico del constructo social que se asocia al mismo. El concepto se desarrolla en la segunda mitad del siglo XX en diversas obras feministas entre las que destaca OAKLEY, A. Sex, Gender and Society. Londres: Ed, Routledge, 1972. Diferenciar el plano biológico del socialmente construido permitió entender los roles asignados a cada género y la consecuente asunción de la mujer como sujeto inferior al hombre. Véase el estudio de ASUA, A. «Las agresiones sexuales en el nuevo código penal: imágenes culturales y discurso jurídico» en RINCÓN, A (Coord.). Análisis del código penal desde la perspectiva de género. Vitoria-Gazteiz: Emakunde-Instituto Vasco de la Mujer, 1998, p. 50. También resulta relevante lo que explica la Oficina del Alto Comisionado de las Naciones Unidas para los Derechos Huma- 
la violencia contra las mujeres9 ${ }^{9}$ Así, por ejemplo, la Declaración sobre la eliminación de la violencia contra la mujer de la Asamblea General de la ONU observa que la violencia contra la mujer abarca la violencia física, sexual y psicológica que se produzca en la familia, en la comunidad en general o que sea perpetrada o tolerada por el Estado (Art. 2) ${ }^{10}$. El mismo dispone que la violencia contra las mujeres se trata de una violación de sus derechos humanos que encuentra su raíz en la discriminación que históricamente sufren las mismas y que ha conducido a su dominación ${ }^{11}$. Del mismo modo, la jurisprudencia internacional y regional reciente también ha ordenado la violencia sexual en el marco de la violencia contra la mujer ${ }^{12}$. Sin embargo, alcanzar este marco de reconocimiento se trata del fruto de una legislación internacional progresiva y paulatina que ha ido definiendo la violencia sexual y desentrañando lo que esta supone para las mujeres.

La agresión sexual y el abuso sexual son los delitos sexuales con más hechos conocidos registrados en España ${ }^{13}$. Llama especialmente la atención el

nos. Los derechos de la mujer son derechos humanos. 2014, p. 38 «La noción de género se refiere a las identidades socialmente construidas, los atributos y los roles asignados a mujeres y hombres» que, dice, dan lugar a relaciones jerárquicas entre hombres y mujeres en favor de los primeros y en detrimento de las segundas.

9 Por mencionar algunos ejemplos, véase la Declaración y Plataforma de Acción de Pekín de la Asamblea General de la ONU aprobada en la $16^{\text {a }}$ sesión plenaria de 15 de septiembre de 1995, párr. 113, la Recomendación General № 19 sobre la violencia contra la mujer del Comité para la Eliminación de la Discriminación contra la Mujer (Comité CEDAW) del 29 de enero de 1992, párr. 6; Recomendación general No 28 relativa al artículo 2 de la Convención sobre la eliminación de todas las formas de discriminación contra la mujer del Comité CEDAW de 16 de diciembre de 2010, párr. 19 y la Recomendación General $N^{0} 35$ sobre la violencia por razón de género contra la mujer por la que se actualiza la Recomendación general no 19 del Comité CEDAW de 26 de julio de 2017, párr. 14

${ }_{10}$ Declaración sobre la eliminación de violencia contra la mujer de la Asamblea General de la ONU de 1993 adoptada por la resolución 48/104 en la 85ª sesión plenaria del 20 de diciembre de 1993. También aborda en su artículo 1 el concepto de «violencia contra la mujer» definiéndolo como «todo acto de violencia basado en la pertenencia al sexo femenino que tenga o pueda tener como resultado un daño o sufrimiento físico, sexual o psicológico para la mujer, así como las amenazas de tales actos, la coacción o la privación arbitraria de la libertad, tanto si se producen en la vida pública como en la vida privada».

11 Ibídem, preámbulo.

12 Véase, entre otros, la Sentencia de la Corte Interamericana de Derechos Humanos. González y otras («Campo algodonero») v México de 16 de noviembre de 2009; el Dictamen del Comité CEDAW Karen Tayag Vertido v Filipinas, Comunicación núm. 18/2008, CEDAW/C/46/D/18/2008 de 22 de septiembre de 2010 y la Sentencia del Tribunal Europeo de Derechos Humanos E.B v Romania Application no. 49089/10 de 19 de marzo de 2019.

13 En 2017, de los hechos conocidos por delitos sexuales, representaron un $75 \%$. Ministerio de Interior, Informe sobre delitos contra la libertad e indemnidad sexual en España, 2018, p. 5. 
crecimiento de los hechos conocidos de abusos sexuales con penetración, que se duplicó de 2012 a $2017^{14}$ (Véase Anexo I), así como el aumento del 22,7\% de agresiones sexuales con penetración en 2018 respecto al año anterior ${ }^{15}$. El presente trabajo se focaliza en el crimen de la violación, uno de los delitos sexuales más graves y debatidos, pues su conceptualización sigue hoy en día desarrollándose en los diferentes sistemas penales. Estos gozan de un gran potencial simbólico para influir en el imaginario colectivo y, de la misma forma pero al contrario, la transformación de la percepción social dirige la constante evolución de los mecanismos legales en la materia. En la realidad actual española, cobra especial relevancia la controversia existente en torno a la concurrencia de violencia o de falta de consentimiento como elemento definitorio de la violación. Es por esto por lo que el objeto primordial del presente trabajo consiste en arrojar algo de luz al mencionado debate, proponiendo una reflexión en torno a la adecuación actual del Código Penal español en materia de violación con respecto a los estándares legales internacionales, y concretamente, europeos.

\section{VIOLENCIA SEXUAL Y VIOLACIÓN: REGULACIÓN INTERNACIONAL}

\section{Desarrollo en el derecho penal internacional.}

A pesar de que la violencia sexual, y en concreto la violación, forman parte de la cotidianeidad de las mujeres - ya sea por ser víctima o por el miedo a serlo ${ }^{16}$ - el derecho internacional ha abordado los crímenes sexuales partiendo de la esfera de los conflictos armados, en la que se cometen las mayores atrocidades. Este desarrollo legal ha aparecido de forma tardía, dejando impunes multiplicidad de actos delictivos del pasado extremadamente graves. Sin embargo, en poco más de un siglo las disposiciones que abordan la violencia sexual han pasado de ser imprecisas prohibiciones que encuentran su origen en la mujer como propiedad del hombre ${ }^{17}$ a convertirse

\footnotetext{
${ }^{14}$ Ibídem.

15 Ministerio del Interior, Infracciones penales registradas en CCAAs, provincias, islas, capitales y localidades con población superior a 30.000 habitantes, 2018, p. 323.

16 WEST, R. «The Difference in Women's Hedonic Lives: A phenomenological critique of feminist legal theory». Wisconsin women's law journal, $\mathrm{n}^{\mathrm{o}} .3,1987$, p. 88: «todas las mujeres, incluso aquellas que nunca han experimentado una agresión sexual, experimentan el miedo a la violación, éste está siempre con nosotras, afecta a nuestras vidas de incontables maneras» y BROWNMILLER, S. Contra nuestra voluntad: hombres, mujeres y violación. Barcelona: Ed. Planeta, 1981.

${ }_{17}$ No es hasta la llegada de la Ilustración cuando la mujer se empieza a considerar un sujeto independiente. DE MIGUEL, A., Neoliberalismo sexual: el mito de la libre elec-
} 
en detallados mandatos que localizan su justificación en la protección de la dignidad y libertad de la mujer, enmarcando esta violencia dentro de los crímenes de guerra y los crímenes de lesa humanidad.

Así, el Lieber Code de $1863^{18}$, aparece como uno de los primeros mecanismos legales que persiguen la violencia sexual. Sus artículos 37 y 44 prohíben vagamente la violencia sexual. Además, parte de la relevancia de este código reside en su utilización para la redacción del $I V$ Convenio de la Haya relativo a las leyes y costumbres de la guerra terrestre de $1907^{19}$. Este último, en su precepto 46, se refiere indirectamente a la violencia sexual al mencionar «el honor y los derechos de la familia». Cabe asimismo destacar la Ley $N^{\circ} 10 \mathrm{del}$ Consejo de Control Aliado que clasifica la violación como crimen de lesa humanidad (Art. 2.1.c) ${ }^{20}$. De esta manera, aunque concebidas como daños ineludibles e inherentes a los conflictos, estas brutalidades se comienzan a visibilizar y su prohibición se comienza a consolidar como parte del derecho internacional consuetudinario ${ }^{21}$. En ese sentido, resultan asimismo trascendentales los juicios de Nuremberg de 1949 ya que, a pesar de que su estatuto ${ }^{22}$ no recogía específicamente el delito de violación y todos estos actos quedaron

ción. Undécima edición. Ed. Cátedra, 2017, p. 255 y SANCHEZ BUSSO, M. «El sistema penal: ¿una herramienta antidiscriminatoria?». Anuario del CIJS, 2008, p. 761.

18 Este código, firmado por el entonces presidente Abraham Lincoln, recogía las instrucciones que los soldados de los ejércitos de los Estados Unidos debían seguir en el campo de batalla. Se conoce como el primer intento en codificar leyes para tiempos de guerra. Instructions for the Government of Armies of the United States in the Field (Lieber Code) de 24 de abril de 1863. Disponible en https://ihl-databases.icrc.org/ihl/ INTRO/110.

19 Convenio IV relativo a las leyes y costumbres de la guerra terrestre, firmado en La Haya el 18 de octubre de 1907 por la Partes Contratantes. Disponible en https://www.icrc. org/es/doc/resources/documents/misc/treaty-1907-regulations-laws-customs-war-onland-5tdm39.htm. Este, junto con el Convenio de la Haya de 1899, resulta ser de gran influencia en el derecho internacional humanitario. KOENIG, K.A., LINCOLN, R. y GROTH, L. The jurisprudence of sexual violence. University of California Berkeley: Human Rights Center, 2011, p. 5.

${ }^{20}$ Control Council Law No. 10, Punishment of Persons Guilty of War Crimes, Crimes Against Peace and Against Humanity, de Official Gazette Control Council for Germany, de 20 de diciembre de 1945 disponible en https://www.legal-tools.org/doc/ffda62/pdf/. Formado por las cuatro potencias vencedoras de la II Guerra Mundial.

${ }^{21}$ ZORRILLA, M. La Corte Penal Internacional ante el crimen de violencia sexual. Universidad de Deusto. Instituto de Derechos Humanos, 2005, p. 18.

${ }^{22}$ Agreement for the prosecution and punishment of the major war criminals of the European Axis firmado en Londres el 8 de agosto de 1945 por el Reino Unido de Gran Bretaña e Irlanda del Norte, los Estados Unidos de América, Francia y la Unión de Repúblicas Socialistas Soviéticas. Disponible en https:/www.un.org/en/genocideprevention/ documents/atrocity-crimes/Doc.2_Charter\%20of\%20IMT\%201945.pdf 
impunes formando parte de un silencio muy criticable $e^{23}$, los juicios contribuyeron jurídicamente mediante la creación de la figura penal Crímenes contra la humanidad, pues esta inédita calificación sería la precursora de leyes posteriores que sí clasificarían así a la violencia sexual ${ }^{24}$. Asimismo, la protección internacional que se iba fraguando frente a los delitos sexuales se plasma y expande en los Convenios de Ginebra de 1949 y sus Protocolos Adicionales, pues el IV Convenio recoge la especial protección de las mujeres «contra la violación, la prostitución forzada y todo atentado a su pudor» (Art. 27) ${ }^{25}$. Se trata del primer acuerdo internacional multilateral que expresamente menciona y prohíbe la violación; se sientan las bases del desarrollo legal ${ }^{26}$. No obstante, este documento ha sido ampliamente criticado, entre otras $\operatorname{cosas}^{27}$, porque la violación no se encuentra enmarcada dentro del artículo 147 del IV Convenio, dejando este crimen fuera de las «infracciones graves» y por tanto no generando en los países la obligación de prohibirlo y perseguirlo ${ }^{28}$.

${ }^{23}$ Durante el trascurso de estos juicios, existía amplia documentación y suficiente evidencia de la comisión de numerosas violaciones. Así lo recogen ZORRILLA, M. La Corte Penal... op. cit, p.16; y FERNÁNDEZ, J. La violencia sexual en el derecho internacional humanitario y el estatuto de Roma. Amnistía Internacional, 2018. Disponible en https://www. amnistia.org/ve/blog/2018/03/5160/la-violencia-sexual-en-el-dih-y-el-estatuto-de-roma

${ }^{24}$ De un modo similar, el Tribunal Militar Internacional para el Lejano Oriente tampoco recogió expresamente la violación ni la violencia sexual, aunque finalmente sí acusó de estos actos a parte del personal del imperio japonés a través de la categoría «failure to prevent atrocities at the command level», lo que supuso el fin de la ocultación de estos crímenes. KOENIG, K.A., LINCOLN, R. y GROTH, L. The jurisprudence... op. cit, p. 5 y 6.

${ }^{25}$ Convenio de Ginebra relativo a la protección debida a las personas civiles en tiempo de guerra de la Conferencia Diplomática para Elaborar Convenios Internacionales destinados a proteger a las víctimas de la guerra, aprobado en Ginebra el 12 de agosto de 1949. Disponible en https://www.icrc.org/es/doc/resources/documents/treaty/treaty-gc4-5tdkyk.htm Muy similares disposiciones se hallan en los artículos 76.1 y 75.2 del Protocolo I Adicional a los Convenios de Ginebra de 1949 relativo a la protección de las víctimas de los conflictos armados internacionales, y el artículo 4.2.e del Protocolo II adicional a los Convenios de Ginebra de 1949 relativo a la protección de las víctimas de los conflictos armados sin carácter internacional, ambos de la Conferencia Diplomática sobre la Reafirmación y el Desarrollo del Derecho Internacional Humanitario Aplicable en los Conflictos Armados, aprobados el 8 de junio de 1977. Disponibles en https://www. icrc.org/es/document/protocolo-i-adicional-convenios-ginebra-1949-proteccionvictimas-conflictos-armados-internacionales-1977 y https://www.icrc.org/es/doc/resources/documents/misc/protocolo-ii.htm respectivamente.

${ }^{26}$ KOENIG, K.A., LINCOLN, R. y GROTH, L. The jurisprudence... op. cit, p. 7 y 2.

${ }^{27}$ El IV Convenio de Ginebra ha sido debatido en cuánto al léxico empleado; sin embargo, es importante tener en cuenta que su contexto histórico, en el que la violación se considera un crimen contra la moral pública y esta es la línea que sigue el documento. FERNÁNDEZ, J. La violencia sexual en el derecho... op. cit.

${ }^{28}$ KOENIG, K.A., LINCOLN, R. y GROTH, L. The jurisprudence... op. cit, p. 8. 
Resulta clave en este punto la formación a principios de los 90 de dos mecanismos legales que impulsaron una jurisprudencia internacional sólida que definiría y prohibiría la violación y la violencia sexual de manera excepcional: el TPIY y el TPIR, dos tribunales ad hoc creados por el Consejo de Seguridad de la $\mathrm{ONU}^{29}$. Ambos tuvieron que conocer significativos casos que les llevaron a dictar resoluciones rupturistas y vanguardistas ${ }^{30}$ que colmaron ciertas lagunas que todavía existían en el derecho internacional en esta materia. Se destacan a continuación sus dictámenes más trascendentales.

En primer lugar, la llamada Sentencia Akayesu ${ }^{31}$ del TPIR resalta por su aportación de una definición conceptual de la violación que atiende al espíritu del delito (párr. 597 y 687) 32: «Una invasión física de naturaleza sexual, cometida en circunstancias que son coercitivas ${ }^{33} \gg$ (párr. 598 y 688). Su importancia reside en que por primera vez se proporciona una definición que recoge los elementos de la violación, es la primera comúnmente aceptada en el Derecho Internacional ${ }^{34}$. Asimismo, este dictamen ofrece una distinción entre violación y violencia sexual, señalando que la última consiste en «Cualquier acto de naturaleza sexual contra una persona en circunstancias coercitivas que no está limitada a la invasión física del cuerpo humano» (párr. $688)^{35}$. En definitiva, esta innovadora sentencia se convirtió en histórica por arrojar luz en la materia de violencia sexual en el escenario internacional.

29 Ambos tribunales son creados a consecuencia de la magnitud de los crímenes cometidos durante los conflictos armados de estos dos territorios, que inquietó a la comunidad internacional. Véase ZORRILLA, M. La Corte Penal... op. cit, p. 41 . El TPIY se crea a través de la Resolución 808 del Consejo de Seguridad de la ONU de 22 de febrero de 1993 (https://undocs.org/es/S/RES/808\%20(1993)) y el TPIR mediante la Resolución 955 del Consejo de Seguridad de la ONU de 8 noviembre de 1994 (https://undocs.org/es/S/ RES/955\%20(1994)).

${ }^{30}$ ZORRILLA, M. La Corte Penal... op. cit, p. 12.

31 Sentencia del Tribunal Penal Internacional para Ruanda de 2 de septiembre de 1998, The Prosecutor v. Jean-Paul Akayesu, ICTR-96-4-A-T en http://www.worldcourts. com/ictr/eng/decisions/1998.09.02_Prosecutor_v_Akayesu.pdf

32 Por primera vez en el panorama internacional, el Tribunal deja atrás la percepción de la violación como un delito contra el honor o la familia y lo aborda como ataque a la dignidad personal. KOENIG, K.A., LINCOLN, R. y GROTH, L. The jurisprudence... op. cit, p. 45.

33 «Las circunstancias coercitivas no tienen por qué ser evidentes por una demostración de fuerza física. Las amenazas, la intimidación, la extorsión y otras formas de coacción que se aprovechan del miedo o la desesperación pueden constituir coerción» (Párr. 688).

${ }_{34}$ BOU FRANCH, V. «Crímenes sexuales en la jurisprudencia internacional». Revista electrónica de Estudios Internacionales, $\mathrm{n}^{\circ}$ 24, Universidad de Valencia, 2012, p.7; VALLEJO TORRES, C. «Delitos contra la libertad sexual y perspectiva de género: una mirada hacia fuera para reflexionar desde dentro». La Ley, $\mathrm{N}^{\circ}$ 9263, 2018, p.2. y KOENIG, K.A., LINCOLN, R. y GROTH, L. The jurisprudence... op. cit, p. 10.

${ }^{35}$ BOU FRANCH, V. «Crímenes sexuales » op.cit, p. 45. 
Alejándose de la definición conceptual de violación del TPIR, la conocida sentencia Furundzija ${ }^{36}$ dictada por el TPIY dispone una descripción mucho más precisa y detallada:

«(i) la penetración sexual, por más leve que sea: (a) de la vagina o ano de la víctima por el pene del autor del delito, o de cualquier otro objeto que éste utilice; o (b) de la boca de la víctima por el pene del autor del delito; (ii) mediante coacción, fuerza o amenaza de uso de la fuerza contra la víctima o una tercera persona» (párr. 185).

Sin embargo, esta descripción fue ampliamente refutada por el TPIR en la sentencia $\mathrm{Musema}^{37}$, pues se inclinó de nuevo por la definición conceptual propuesta en el caso Akayesu (párr. 229) que atiende a la esencia del delito $^{38}$.

En contraposición, el TPIY continuó empleando su definición detallada de violación más tarde en la sentencia Kunarac ${ }^{39}$ (párr. 438). No obstante, el tribunal matizó y complementó su propia definición a través de dicha resolución, fundamentando el actus reus del delito no ya en la «coacción, fuerza, o amenaza del uso de fuerza», sino en la ausencia de consentimiento ${ }^{40}$ : «en la cual dicha penetración ocurre sin el consentimiento de la víctima. La víctima debe dar su consentimiento para que se lleven a cabo estos propósitos de forma voluntaria, como resultado de su voluntad, y debe evaluarse este consentimiento dentro del contexto de las circunstancias que rodean al hecho» (párr. 460) ${ }^{41}$. La resolución

${ }^{36}$ Sentencia del Tribunal Penal Internacional para la Antigua Yugoslavia de 10 de diciembre de 1998, The Prosecutor v. Anto Furundzija, no IT-95-17/1-T disponible en http://www.icty.org/x/cases/furundzija/tjug/en/fur-tj981210e.htm

${ }^{37}$ Sentencia del Tribunal Penal Internacional para Ruanda de 27 de enero del 2000. The prosecutor v. Alfred Musema, no ICTR-96-13-A disponible en https://www.legaltools.org/doc/1 fc6ed/pdf/

${ }^{38}$ En este dictamen el TPIR reconoce lo dispuesto por el TPIY en el párrafo 179 de Furundzija respecto a la tendencia existente en las legislaciones nacionales hacia una ampliación de la definición de violación. Sin embargo, por este mismo dinamismo, el TPIR considera que una definición conceptual es preferible a una detallada en aras de acomodarse a la evolución de las normas penales (párr. 228).

39 Sentencia del Tribunal Penal Internacional para la Antigua Yugoslavia de 22 de febrero de 2001, The prosecutor v. Dragoljub Kunarac, Radomir Kovac y Zoran Vukovic. $\mathrm{N}^{\mathrm{o}}$ IT-96-23-T\& IT-96-23/1-A disponible en http://www.icty.org/x/cases/kunarac/tjug/ en/kun-tj010222e.pdf

${ }^{40}$ El TPIY se basa en que el principio básico subyacente común a todos los sistemas legales analizados por el tribunal en Furundzija y en la presente Kunarac consiste en que la penetración sexual constituye un delito de violación si no es consentida o voluntaria por parte de la víctima (párr. 440 y 453-457). Además, al incluir la falta de consentimiento, el tribunal pone el foco en la violación de la autonomía sexual (párr. 440 y 441).

${ }^{41}$ Hablar de falta de consentimiento supuso al TPIY el deber de analizar este concepto, llegando a la conclusión de que la ausencia de consentimiento es evidente cuando 
Kunarac fue revisada por la Sala de Apelaciones ${ }^{42}$, lo que comenzó a zanjar la confrontación jurisprudencial entre ambos tribunales ${ }^{43}$. La Sala, optando por la definición del TPIY (es decir, la definición detallada en vez de la conceptual) otorgada en Furundzija y matizada en Kunarac, reafirmó lo convenido en esta última en torno a la falta de consentimiento como elemento clave. Así, sostuvo que la fuerza no es un elemento per se en la violación sino uno de los factores que viciarían el consentimiento de la víctima ${ }^{44}$, pues considerar lo contrario podría permitir a los perpetradores evadir su responsabilidad por una actividad sexual no consensuada aprovechándose de circunstancias coercitivas sin que se aprecie fuerza física (párr. 129). La relevancia de todo esto reside en que se abandona la idea de que todas las relaciones sexuales sin fuerza o amenaza del uso de la fuerza son consensuadas ${ }^{45}$ y se entiende que el delito de violación puede constituirse sin la concurrencia de estas.

Así, se observa cómo las diferencias jurisprudenciales entre los dos tribunales, lejos de fragmentarlo, enriquecieron el Derecho penal internacional en materia de delitos sexuales a través de fundamentadas argumentaciones jurídi$\mathrm{cas}^{46}$. De esta forma, su jurisprudencia hoy en día consolidada abrió el camino e influyó inmensamente en los posteriores mecanismos legales internacionales que trataron la materia, este es el caso de la CPI y su Estatuto de Roma ${ }^{47}$. Así,

existe fuerza, amenaza del uso de fuerza o aprovechamiento de una persona que no puede resistir la actividad sexual (párr. 458). Asimismo, el Tribunal identifica tres categorías de factores que clasificarían la actividad sexual en el crimen de violación: i) la fuerza o la amenaza del uso de fuerza hacia la víctima o un tercero ii) la fuerza u otras circunstancias específicas que hacen a la víctima particularmente vulnerable o le niegan su capacidad para rechazar de manera informada iii) la falta de consentimiento de la víctima (párr. 442).

42 Sentencia de la Sala de Apelaciones del Tribunal Penal Internacional para la Antigua Yugoslavia de 12 de junio de 2002, The prosecutor v. Dragoljub Kunarac, Radomir Kovac y Zoran Vukovic, no IT-96-23 \& IT-96-23/1-A disponible en http://www.icty. org/x/cases/kunarac/acjug/en/kun-aj020612e.pdf

${ }^{43}$ BOU FRANCH, V. «Crímenes sexuales »op. cit, p 14.

${ }_{44}$ Aunque su concurrencia «proporciona evidencia clara de la ausencia de consentimiento» puede haber factores distintos a la fuerza que podrían hacer que un acto de penetración sexual no sea consensual (párr. 129).

45 ZORRILLA, M. La Corte Penal... op. cit, p. 51.

46 BOU FRANCH, V. «Crímenes sexuales » op. cit, p. 45. También supuso avances significativos la jurisprudencia de otros tribunales especiales como el de Sierra Leona, el de Camboya y el de Timor Oriental, puede analizarse la explicación de KOENIG, K.A., LINCOLN, R. y GROTH, L. The jurisprudence... op. cit, p. 14.

47 Estatuto de Roma de la Corte Penal Internacional de Naciones Unidas, de 17 de julio de 1998, A/Conf. 183/9 que entra en vigor el 1 de julio de 2002. Instrumento de ratificación de España, Boletín Oficial del Estado, 27 de mayo de 2002, nº 126, p. 18824. 
el documento «Elementos de los crímenes» ${ }^{48}$, define los elementos constitutivos de violencia sexual (Arts 7 1) g)-6 y 8 2) b) xxii)-6) y violación (Arts 7 1) g)-1 y 8 2) b) xxii)-1) $)^{49}$ basándose en gran medida en la jurisprudencia de los tribunales ad hoc. Sin embargo, la CPI también goza de preceptos progresistas y su estatuto es el primer tratado internacional que tipifica los crímenes sexuales en una categoría autónoma ${ }^{50}$. Además, incluye en esta nuevos tipos penales como la violación, la esclavitud sexual, la prostitución forzada, el embarazo forzado, la esterilización forzada y otros abusos sexuales (Art. 7.1.g). Se trata de la enumeración escrita más completa hasta la fecha ${ }^{51}$. Igualmente, gracias al Estatuto de Roma, por primera vez en el derecho internacional los delitos de violencia sexual se equiparan a las infracciones graves (Art. $8^{52}$ ). Estas disposiciones de la CPI produjeron un gran impacto normativo y simbólico en el Derecho penal internacional.

\section{El marco legal en Europa}

En la región europea, los mecanismos legales internacionales han incorporado la falta de consentimiento como elemento central en la violación de manera relativamente reciente. Así, el Comité de Ministros del Consejo de Europa ya señaló en 2002 que las legislaciones nacionales debían penalizar cualquier acto sexual cometido sin consentimiento, aunque la víctima no mostrara signos de oponer resistencia ${ }^{53}$. También en esta línea, al hilo de la

Gracias al TPIY y al TPIR, esta corte cuenta actualmente con un muy propicio espacio en el que poder seguir avanzando a través de la casuística que se le plantea.

48 Proyecto de texto definitivo de los Elementos de los Crímenes de la Comisión Preparatoria de la Corte Penal Internacional de 2 de noviembre del 2000, PCNICC/2000/1/ Add.2. Este texto guía a la CPI en su labor de interpretación y aplicación de los preceptos del Estatuto de Roma.

${ }^{49}$ La Comisión Preparatoria se decantó claramente por la definición detallada de Furundzija al elaborar este documento. Además, aunque se observa en el inciso final «o se haya realizado contra una persona incapaz de dar su libre consentimiento», debido al factor temporal la Comisión no pudo tener en cuenta la matización y argumentación de la sentencia Kunarac en torno a la falta de consentimiento. BOU FRANCH, V. "Crímenes sexuales »op. cit., p. 17 y 18.

${ }^{50}$ BOU FRANCH, V. «Crímenes sexuales » op. cit., p. 43 y VALLEJO TORRES, C. «Delitos contra la libertad sexual...»op. cit., p. 2.

${ }^{51}$ KOENIG, K.A., LINCOLN, R. y GROTH, L. The jurisprudence ... op. cit., p. 17.

${ }^{52}$ Se entiende por crímenes de guerra «vi) Cometer actos de violación, esclavitud sexual, prostitución forzada, embarazo forzado, esterilización forzada o cualquier otra forma de violencia sexual que constituya también una violación grave del artículo 3 común a los cuatro Convenios de Ginebra»

${ }_{53}$ Recomendación No. R (2002) 5 adoptada el 30 de abril de 2002 por el Comité de Ministros del Consejo de Europa tomado de Amnistía Internacional. Right to be free from 
resolución del caso M.C. v Bulgaria, el Tribunal Europeo de Derechos Humanos sostuvo en 2003 que el factor decisivo en el delito de violación era la falta de consentimiento y no la prueba de fuerza del sujeto activo ni la resistencia de la víctima ${ }^{54}$. En dicha ocasión, el tribunal también indicó que exigir pruebas de resistencia física en los delitos sexuales abre la posibilidad a dejar impunes ciertos tipos de violaciones, poniéndose en peligro la protección efectiva de la autonomía sexual de la víctima ${ }^{55}$.

Cobra especial interés en la región el Convenio sobre Prevención y Lucha contra la Violencia contra la Mujer y la Violencia doméstica ${ }^{56}$ (referido en adelante como Convenio de Estambul), que es el único tratado internacional europeo que específicamente aborda la violencia contra las mujeres. A pesar de que la Convención de Belem do Pará ${ }^{57}$ (para la región de Latinoamérica) y el Protocolo de Maputo $^{58}$ (dirigido al continente africano) también regulan esta materia, el Convenio de Estambul aparece como el tratado regional que con mayor exhaustividad en todo el mundo aborda la violencia contra las mujeres, su prevención y su enjuiciamiento (véase Anexo II). El documento, ratificado por 34 países en la región europea $^{59}$, y que entró en vigor en España hace hoy casi cinco años, reconoce e incluye la violencia sexual entre las diferentes formas de ejercer la violencia de género ${ }^{60}$.

rape. Overview of legislation and state of play in Europe and international human right standards. 2018, p. 6 disponible en https://www.amnesty.org/en/documents/ eur01/9452/2018/en.

${ }^{54}$ Este caso se convirtió en un importante punto de referencia que además estableció que la falta de violencia no se podía equiparar al consentimiento. Sentencia del Tribunal Europeo de Derechos Humanos de 4 de diciembre de 2003 No. 39279/98, (M.C. v Bulgaria), ECHR 2203XII, párrafos 85, 127, 138, 159 y 163, entre otros.

55 Ibídem, párrafo 166.

${ }^{56}$ Convenio sobre Prevención y Lucha contra la Violencia contra la Mujer y la Violencia doméstica, Consejo de Europa, en Estambul el 12 de abril de 2011. Ratificado por España el 10 de abril de 2014. Publicado en el BOE no. 137, de 6 de junio de 2014, p. 42946-42976.

${ }^{57}$ Convención Interamericana para Prevenir, Sancionar y Erradicar la Violencia contra la Mujer, la Organización de Estados Americanos, en Belem do Pará el 9 de junio de 1994.

58 Protocolo Adicional a la Carta Africana sobre los Derechos Humanos y de los Pueblos, Unión Africana, en Maputo el 11 de julio de 2003.

59 A 20/06/2019 el Convenio ha sido ratificado por: Albania, Andorra, Austria, Bélgica, Bosnia Herzegovina, Croacia, Chipre, Dinamarca, Estonia, Finlandia, Francia, Georgia, Alemania, Grecia, Islandia, Irlanda, Italia, Luxemburgo, Malta, Mónaco, Montenegro, Holanda, Macedonia del Norte, Noruega, Polonia, Portugal, Rumanía, San Marino, Serbia, Eslovenia, España, Suecia, Suiza y Turquía. Consejo de Europa. Chart of signatures and ratifications of Treaty 210, disponible en https:/www.coe.int/en/web/ conventions/full-list/-/conventions/treaty/210/signatures

${ }^{60}$ Artículo 3 - Definiciones: Mediante el término «violencia contra las mujeres» se designan «todos los actos de violencia basados en el género que implican o pueden impli- 
El Convenio de Estambul también coloca en el foco principal la ausencia de consentimiento, ${ }^{61}$ el hecho de que la víctima no desee la penetración, dejando a un lado los medios comisivos utilizados a tal efecto ${ }^{62}$. Además, declara que el consentimiento debe prestarse voluntariamente como manifestación del libre arbitrio de la persona considerado en el contexto de las condiciones circundantes ${ }^{63}$. Sin embargo, sólo un pequeño número de los países que han ratificado el convenio lo han incorporado plenamente recogiendo la falta de consentimiento como elemento definitorio del crimen de violación y descartando que el uso de la violencia o su amenaza sean requisitos necesarios. En este sentido, aparece como ejemplo Alemania, que en 2017 aprobó un proyecto de ley denominado «No es No» dirigido a penalizar las conductas que fuercen a las personas contra su voluntad manifiesta, pudiendo consistir esta última en palabras o gestos de disconformidad ${ }^{64}$. En la misma línea, Suecia vincula la comisión de violación con la falta de consentimiento sexual expreso. Por su parte, Irlanda y Bélgica definen la violación como las relaciones sexuales sin consentimiento, aunque estas lo llevan haciendo desde 1981 y 1989, respectivamente ${ }^{65}$. Constituyen otros ejemplos Chipre, Islandia, Luxemburgo ${ }^{66}$, y recientemente, Portugal. No obstante, la realidad es que la amplia mayoría de los países europeos no han incorporado el contenido del mismo a sus legislaciones, cuyas definiciones legales de violación se basan

car para las mujeres daños o sufrimientos de naturaleza física, sexual, psicológica [ ]».

${ }_{61}$ Art. 36.1 «Las Partes adoptarán las medidas legislativas o de otro tipo necesarias para tipificar como delito, cuando se cometa intencionadamente: a. la penetración vaginal, anal u oral no consentida, con carácter sexual, del cuerpo de otra persona con cualquier parte del cuerpo o con un objeto; b. los demás actos de carácter sexual no consentidos sobre otra persona; c. el hecho de obligar a otra persona a prestarse a actos de carácter sexual no consentidos con un tercero»"

${ }^{62}$ Sin perjuicio de que estos medios comisivos puedan ser considerados como circunstancias agravantes, contempladas en el Articulo 46 del Convenio. Como por ejemplo, «que el delito haya sido precedido o se haya acompañado de una violencia de extrema gravedad» o que «haya provocado graves daños físicos o psicológicos a la víctima».

${ }^{63}$ Art. 36. 2 del Convenio de Estambul. Adicionalmente, el Informe Explicativo del convenio observa que corresponde a las partes la redacción específica de lo que significa el libre consentimiento y los factores que lo obstaculizan. Consejo de Europa. Explanatory Report to the Council of Europe Convention on preventing and combating violence against women and domestic violence Istanbul, 2011, párrafo 193.

${ }^{64}$ Código Penal de Alemania, Strafgesetzbuch, párrafo 177 tomado de DE VICENTE MARTÍNEZ, R. «El delito de violación: problemas que plantea su vigente redacción» en FARALDO CABANA, P y ACALE SÁNCHEZ, M (Dirs.). La manada. Un antes y un después en la regulación de los delitos sexuales en España. Valencia: Ed. Tirant lo Blanch, 2018, p. 193.

${ }_{65}$ Amnistía Internacional. Right to be free... op. cit., p. 9 y 11

${ }^{66}$ Amnistía Internacional. Right to be free... op. cit., p. 9 
en la fuerza o la amenaza, de modo que cuando aquellas no acaecen no concurre este delito ${ }^{67}$. Tan sólo algunos de estos son Finlandia, Francia, Países Bajos, Noruega, República Checa y Suiza ${ }^{68}$.

\section{III.LA VIOLACIÓN EN EL CÓDIGO PENAL ESPAÑOL Y SUS LÍMITES CON EL ABUSO SEXUAL}

\section{Desde la honestidad de la mujer hasta la libertad sexual de todos y todas}

La legislación de la violencia sexual en los sistemas penales se ha caracterizado tradicionalmente por la expresión de una visión patriarcal ${ }^{69}$. Prueba de ello resulta la tutela de la «decencia», la «familia» o la «moral pública» ${ }^{70}$ que ha servido, y todavía sirve ${ }^{71}$ en muchos países para sancionar los delitos sexuales perpetrados desproporcionadamente hacia las mujeres, de forma que se perpetúa la idea de que estas son las depositarias de la moral de la familia o la comunidad, avivándose el control de su sexualidad ${ }^{72}$. Esto es, la

${ }^{67}$ Amnistía Internacional. Right to be free... op. cit., p. 12.

68 Ibídem.

${ }^{69}$ De hecho, los primeros códigos penales minimizaban y justificaban toda violencia contra la mujer. Bodelón, E. Violencia de género y las respuestas de los sistemas penales. Buenos Aires: Didot, 2012, p. 15.

70 Amnesty International. Right to be free... op.cit., p. 14; Equality now. The world's shame. The Global Rape Epidemic. How laws around the world are failing to protect women and girls from sexual violence, 2017, p. 21 disponible en https://www.equalitynow.org/the_world_s_shame_the_global_rape_epidemic_how_laws_around the_world are_failing_to_protect_women_and_girls_from_sexual_viōence; Naciones Ū Unidas. Hañdbook for Legislation on Viōence against Women, United Nations Entity for Gender Equality and the Empowerment of Women, 2010, p. 24 disponible en http://www.unwomen.org/en/digital-library/publications/2012/12/handbook-for-legislation-on-violenceagainst-women

${ }^{71}$ A modo de ejemplo, en Bélgica la violación se recoge bajo el título «Crímenes en contra del orden de las familias y la moral pública» Código Penal de Bélgica, de 8 de junio de 1867, Título VII, disponible en www.ejustice.just.fgov.be/cgi_loi/loi_al.pl?language= fr\&caller $=$ list $\& \mathrm{cn}=1867060801 \& \mathrm{la}=\mathrm{f} \&$ fromtab $=$ loi\&tri $=\mathrm{dd}+\mathrm{as}+\mathrm{rank} \# \mathrm{LNKR0127.} \mathrm{En}$ Países Bajos estas agresiones se enmarcan en ofensas a la «moral pública». Código Penal de Países Bajos, de 3 marzo de 1881, Parte XIV, disponible en www.legislationline.org/ documents/section/criminal-codes.

72 De hecho, en algunas jurisdicciones la víctima podría ser acusada de fornicación (si está soltera) o de adulterio (si está casada) en caso de no poder probar la violación o la agresión sexual. Equality now, The world's shame... op. cit., p. 22. Además, en tiempos de guerra, cuando se perpetra violencia sexual contra las mujeres, se percibe que es el honor de los hombres de su comunidad el que se ve perjudicado. Special Rapporteur on 
sumisión femenina forma parte de la propia normatividad ${ }^{73}$. De este y otros modos las normas jurídicas se han encargado de reforzar y difundir los estereotipos de género que históricamente han colocado a la mujer en un plano inferior al del hombre justificándose en un supuesto orden «natural» $»^{74}$. No obstante, la tendencia actual ${ }^{75}$ es la redirección hacia la tutela de la autonomía sexual ${ }^{76}$, con lo que se pretende atender a la seguridad y libertad sexual de la mujer concebida como sujeto de derechos en sí misma. En España este camino no se ha trazado de manera distinta.

El primer Código Penal español de 1822, que sólo contemplaba que las víctimas de violación fueran mujeres, contenía un agravante en caso de que esta fuera casada (Art. 669) y un atenuante en caso de ser «mujer pública» (Art. 670). Se pone de manifiesto aquí un trasfondo de moralidad, pues no se brindaba la misma tutela a todas las mujeres sino que las consideradas honestas eran merecedoras de mayor protección ${ }^{77}$. Sin embargo, la rúbrica «Delitos contra la honestidad»

Violence against Women. 15 years of the United Nations Special Rapporteur... op.cit., p. 37.

73 POSADA, L. «Otro género de violencia. Reflexiones desde la teoría feminista como teoría crítica». Revista Asparkía, № 19, 2008, p. 58 disponible en: https://dialnet. unirioja.es/descarga/articulo/3171182.pdf

${ }^{74}$ ASUA, A. «Las agresiones sexuales... op.cit., p. 2.

75 Por ejemplo, gran cantidad de países latinoamericanos como Argentina, Brasil, y Ecuador han modificado sus códigos penales dejando atrás el perjuicio al «honor» o la «moral». Así como la reforma del Código Penal turco que pasó de recoger estos delitos como crímenes «en contra de las costumbres morales y la sociedad» a «en contra del individuo» en 2004 que además, como hizo el código sueco en 1998, eliminó todas las referencias a la moral, la castidad y el honor. Naciones Unidas. Handbook for Legislation... op. cit., p. 24.

76 CEDAW, Recomendación general num. 35 sobre la violencia por razón de género contra la mujer, por la que se actualiza la recomendación general num. 19, 2017, párr. 29.e; Naciones Unidas. Handbook for Legislation ... op. cit., p. 24. Special Rapporteur on Violence against Women, 15 years of the United Nations Special Rapporteur... op. cit., p. 37.

77 Esta rebaja de la pena desaparece posteriormente, sin embargo se recupera en el Código penal de 1928 (Art. 600). Para justificar esta reintroducción, la Comisión de Codificación en 1927, al presentar el que posteriormente fue el Código penal de 1928, señaló que «la gran atenuación de la pena responde al hecho de que tal delito, a diferencia de la violación de la mujer honesta, que tiene un doble carácter contra la honestidad y la libertad, sólo puede considerarse como un delito contra la libertad». Comisión de Codifica-

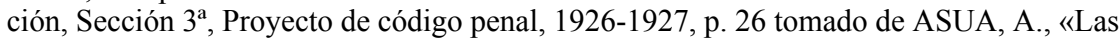
agresiones sexuales » op.cit., p. 13. En esta misma línea se pronunciaba parte de la doctrina de la época, como PACHECO, J. F., El código penal concordado y comentado. Tomo III. Madrid: 1849, p. 127 disponible en http://fama2.us.es/fde/ocr/2007/codigoPenalConcordadoT2.pdf que señaló «¿Debe la ley garantizar del mismo modo contra esos brutales arrebatos a una prostituta que a una virgen, a la que vive con completa holgura que a la que educa sus hijos en el hogar doméstico?». 
aparece por primera vez en el Código de 1848. Desde esta perspectiva, la significación de la violación reside únicamente en la posible alteración del orden familiar y la pérdida de la reputación de la mujer ${ }^{78}$, que se entremezcla con el honor masculino por la visión androcéntrica de la sexualidad femenina ${ }^{79}$. Por su parte, la doctrina del periodo defendió que la resistencia de la víctima ha de ser perseverante y constante, no siendo suficiente la mera negativa ${ }^{80}$. La LO 3/1989, de 21 de junio, de actualización del Código Penal de 1944 trajo consigo una importante novedad: el cambio de rúbrica a «Delitos contra la libertad sexual» ${ }^{81}$. Esto evidencia un incuestionable progreso, pues, como indica ASUA, la tutela de la honestidad suponía la salvaguarda de un orden en el que la mujer y su status social estaban definidos en función de su pertenencia a un varón, y el nuevo enfoque desde la libertad partía del derecho de toda persona a la libre toma de decisiones relativas a su sexualidad, concebida esta última como una manifestación positiva para el desarrollo personal ${ }^{82}$. Esto es, los tipos penales pasan a orientarse hacia el castigo de las conductas que dificulten la libre expresión sexual ${ }^{83}$. Además, al ser el bien jurídico un instrumento que legisladores y magistrados utilizan para legitimar sus opciones de regulación y sus argumentaciones jurisprudencia$l^{8}{ }^{84}$, este desplazamiento hacia la tutela de la libertad logró redirigir los discursos jurisprudenciales, a pesar de que rancios patrones tradicionales persistieran a través de los años ${ }^{85}$. Asimismo, esta ley, utilizando un término sexualmente neutro,

78 ASUA, A. «Las agresiones sexuales...» op. cit., p. 20.

79 SANCHEZ BUSSO, M. El sistema penal...op.cit., p. 764. En este mismo sentido, BODELÓN, E. «Cuestionamiento de la eficacia del Derecho penal en relación a la protección de los intereses de las mujeres» en Análisis del Código penal desde la perspectiva de género. Instituto Vasco de la Mujer, Vitoria-Gasteiz, 1998, p. 185 señala que la tipificación de la violación respondía a la protección del honor del hombre y no al daño de la mujer, a la construcción de un modelo de sexualidad femenina y masculina y no a garantizar la libertad de las mujeres.

${ }^{80}$ Por ejemplo, así lo estima CUELLO CALÓN, E., Derecho penal. Tomo II. Parte especial, Barcelona: Ed. Bosch, 1949, p. 532.

${ }^{81}$ Más adelante, el concepto de «indemnidad sexual» se introduce en la rúbrica con la LO 11/1999, de 30 de abril, de modificación del Título VIII del Libro II del Código Penal atendiendo a los casos en los que estaban involucrados menores y personas con discapacidad, como venían reclamando algunos autores como MUÑOZ CONDE, F. «Los delitos contra la libertad sexual» en Estudios penales y criminológicos. № 13, 1990, p. 271-277.

${ }^{82}$ ASUA, A., «Las agresiones sexuales...» op. cit., p. 4 y 20.

${ }^{83}$ GOENAGA OLAIZOLA, R. «Delitos contra la libertad sexual en Estudios sobre el nuevo código penal español», 1995. Eguzkilore, Cuaderno del instituto vasco de criminología. $\mathrm{N}^{\mathrm{o}} 10$ extraordinario, 1997, p. 96.

${ }^{84}$ LASCURAÍN SANCHEZ, Juan Antonio. «Bien jurídico y legitimidad de la intervención penal». Revista chilena de derecho. Vol. 22 n 2, 1995, p. 252.

${ }^{85}$ ASUA, A. «Las agresiones sexuales...» op. cit., p. 23 y 38 y CUGAT MAURI, M. «La ambivalencia de la protección de la libertad sexual. Jurisprudencia del Tribunal Su- 
abre la posibilidad de que el hombre sea también sujeto pasivo del delito de violación ${ }^{86}$. Así, se observa cómo el derecho penal español empieza a incorporar una visión más comprometida con la igualdad que le ha llevado a experimentar una intensa metamorfosis, si bien todavía resta un largo camino que recorrer.

\section{Una primera aproximación y la violencia en la agresión sexual}

Actualmente, según nuestro Código Penal, y bajo la denominación de agresión sexual (Arts 178-180) ${ }^{87}$, es constitutivo de violación el ataque a la libertad sexual que consista en acceso carnal en el que medie violencia ${ }^{88} \mathrm{o}$ intimidación ${ }^{89}$. El capítulo de abusos sexuales (Arts 181-182) también tipifica el acceso carnal ${ }^{90}$ en el que el sujeto activo no tiene el consentimiento de la víctima ${ }^{91}$. No obstante, la concurrencia de «violencia o intimidación» determina la constitución de una figura penal u otra. Por tanto, de acuerdo a nuestro código, cuando el acceso carnal no esté acompañado por alguno

premo sobre el delito de violación». Jueces para la democracia, №20, 1993, p. 77.

${ }^{86}$ FARALDO CABANA, P. «Evolución del delito de violación en los códigos penales españoles. Valoraciones doctrinales» en FARALDO CABANA, P. y ACALE SÁNCHEZ, M. (Dirs.). La manada. Un antes y un después op. cit., p. 47

${ }^{87}$ Este trabajo hace referencia a estos delitos cometidos contra mayores de 16 años, lo relativo a las agresiones y abusos sexuales contra víctimas menores de dicha edad se regula en el Art. 183 del Código Penal de 1995.

${ }_{88}$ Tradicionalmente se utilizaba el término «fuerza». Este cambio introducido por el código de 1995 se debió a que este concepto se vinculaba a la ejercida sobre las cosas, mientras que el de violencia se refiere a la practicada sobre las personas. DE VICENTE MARTÍNEZ, R. «El delito de violación » op.cit., p. 183.

${ }^{89}$ Este se trata del tipo cualificado, dejando al básico (Art. 178) una aplicación subsidiaria del primero para los casos en los que el ataque no alcanza la intensidad del acceso carnal.

90 «Acceso carnal por vía vaginal, anal o bucal, o introducción de miembros corporales u objetos por alguna de las dos primeras vías» Acción nuclear común a los Arts 179 («De las agresiones sexuales») y 181.4 («De los abusos sexuales») del Título VIII del Libro II del Código Penal de 1995. Se trata del atentado a la libertad sexual en su modalidad más grave. Tras una tediosa evolución legislativa, esto supone aceptar que los accesos carnales con pene, con objeto y los digitales y linguales revisten la misma gravedad. ACALE SANCHEZ, M. «Tratamiento penal de la violencia sexual, la forma más primaria de violencia de género» en FARALDO CABANA, P y ACALE SÁNCHEZ, M (Dirs.). La Manada. Un antes y un después op. cit., p. 80.

91 Ambas figuras comparten algunos elementos típicos. La ausencia de consentimiento es un elemento típico negativo común a ambas figuras, implícito en las agresiones sexuales, y explícito en los abusos. FARALDO CABANA, P. y RAMON RIBAS, E. «La sentencia de La Manada y la reforma de los delitos de agresiones y abusos sexuales en España» en FARALDO CABANA, P y ACALE SÁNCHEZ, M (Dirs.). La Manada. Un antes y un después op.cit., p. 253. 
de estos dos elementos e intervengan otros medios comisivos (como el prevalimiento, el engaño o la anulación de la voluntad de la víctima) no existe violación y nos colocamos ante la figura de los abusos sexuales. Consecuentemente, el primer criterio para su clasificación en la tipificación es el grado de lesión de la libertad sexual, siendo el segundo criterio la intensidad del ataque ${ }^{92}$.

Siguiendo con esta distribución, las agresiones sexuales violentas constituyen el mayor grado de ataque a la libertad sexual ${ }^{93}$. Señala DE VICENTE MARTÍNEZ, que esta violencia a la que hace referencia el código (Art. 178) se refiere a la violencia física, la vis phisica o absoluta que se trata de cierta cantidad de energía que proyectada contra la víctima o que recae sobre ella y que se manifiesta a través de hechos materiales como golpes, y empujones. ${ }^{94}$ Por lo que respecta a la reiterada doctrina del TS, esta violencia consiste en el empleo de fuerza física ${ }^{95}$ que ha de «considerarse suficiente para doblegar la voluntad del sujeto pasivo. No es necesario que esa fuerza física sea irresistible, ni invencible» desde un punto de vista objetivo, pues «no puede exigirse a la víctima que oponga resistencia hasta poner en riesgo serio su integridad física, sino que basta que sea idónea según las características del caso $»{ }^{96}$. Esto es, ha de ser idónea para impedir a la víctima actuar bajo su

92 DÍEZ RIPOLLÉS, J. L. «El «No es no». El País. 2018, disponible en https://elpais. com/elpais/2018/05/03/opinion/1525363530_373340.html y ASUA, A. «Agresiones sexuales...»op.cit., p. 24. Es más, las numerosas modificaciones legislativas del código en relación a estos delitos han puesto de manifiesto la dificultad de su tipificación, hasta el punto de que el Tribunal Supremo ha calificado la vigente regulación de los delitos contra la libertad sexual como «laberíntica» (STS nº 411/2014, de 26 de mayo, F. j. 4; STS nº. 553/2014, de 30 de junio, F. j. 8 y STS no $.355 / 2015,28$ de mayo, F. j. 12).

93 Según A, ASUA. "Las agresiones sexuales » op. cit., p. 25 en la agresión violenta se sitúan los supuestos con el máximo desvalor en cuanto a desprecio y vejación a la que se somete a la víctima.

${ }^{94}$ De modo que se alcance razonablemente la conclusión de que el acto sexual no habría tenido lugar sin el recurso a la violencia. DE VICENTE MARTINEZ, R. «El delito de violación » op. cit., p.184. Sin embargo, no se requiere en ningún caso que se ocasionen lesiones. STS n ${ }^{\circ}$. 216/2016 de 24 de abril, F. j. 7,

${ }_{95} \mathrm{STS} \mathrm{n}^{\circ} .914 / 2008$, de 22 de diciembre, F. j. 5.

96 Entre otras muchas, STS n ${ }^{\circ} .9 / 20156$, de 21 de enero, F. j. 1; STS no. 102/2014, de 18 de febrero, F. j. 2; STS No 413/2004 de 31 de marzo, F. j. 4. Por ejemplo, atendiendo a la mencionada relevancia de las circunstancias concretas de cada caso, se observa como en el caso de víctimas menores de edad el TS ha señalado la concurrencia de violencia en «el hecho de agarrar fuertemente del brazo a la niña» (STS nº.919/2003, de 19 de junio, F. j. 1) o en la sujeción de una menor de 13 años por los hombros (STS n'. 914/2008, de 22 de diciembre F. j. 5) y, sin embargo, no se ha considerado así la sujeción la mano de los brazos de la mujer víctima por encima de su cabeza (STS n ${ }^{\circ} .460 / 2017$, de 21 de junio, F. j. 5). GAVILÁN RUBIO, M. «Agresión sexual y abuso con prevalimiento: análisis de la reciente jurisprudencia». Revista de Derecho, Empresa y Sociedad, № 12, 2018, p. 88. 
autodeterminación ${ }^{97}$. Ulteriormente, el TS también ha afirmado ${ }^{98}$ que «el tipo penal únicamente requiere la violencia por el acusado y no hace mención a la resistencia que debiera oponer la víctima», no obstante la sentencia sí menciona la relevancia de la «manifiesta y explícita oposición de la víctima», aunque se sostiene que esta podrá ser pasiva «porque lo esencial es que el agresor actúe contra la voluntad de la víctima» y la venza por la fuerza.

A raíz de lo expuesto anteriormente, puede colegirse que la distinción entre las figuras de la agresión y el abuso sexual resultaría diáfana, pues las diferentes conductas se irán perfectamente enmarcando en una u otra en función de la concurrencia de los elementos de violencia o intimidación, que delimitan ambas figuras de manera sencilla. Sin embargo, la realidad es muy diferente, pues siendo cierto que las agresiones violentas no generan demasiado debate doctrinal ni jurisprudencial, la proximidad entre las agresiones en las que media la intimidación y el abuso sexual con prevalimiento hace que su diferenciación sea extremadamente compleja, resultando ser el punto de mayor acercamiento entre ambas figuras. No obstante, las distintas consecuencias penológicas y, sobre todo, calificativas de encontrarse a un lado u otro de esta fina línea son determinantes, ¿son verdaderamente tan diferentes el desvalor de acción y de resultado de las agresiones sexuales intimidatorias y el del abuso sexual con prevalimiento para derivar en unos efectos tan dispares?

\section{La agresión sexual intimidatoria con acceso carnal y el abuso sexual con prevalimiento con acceso carnal: problemas de distinción}

\subsection{La intimidación en las agresiones sexuales con acceso carnal}

Mientras que la violencia actúa contra el físico de la víctima, la intimidación es de naturaleza psíquica y recae sobre la psique del sujeto pasivo produciendo temor ${ }^{99}$. Para la Real Academia Española, intimidar significa «causar o infundir miedo, inhibir». Sin embargo, en el marco de las

Pues «la voluntad de los niños es más fácil de someter» (STS nº. 6095/2008, de 5 de noviembre, F. j. 10).

${ }_{97}$ Entre otras muchas, STS no ${ }^{\circ}$ 578/2004, de 26 de abril, F. j. 1; STS nº 1714/2001, de 2 de octubre, F. j. 4; STS no . 834/2014, de 10 de diciembre, F. j. 3. Este criterio también es utilizado para los casos de intimidación STS n ${ }^{\circ}$. 9/2016, de 21 de enero, F. j. 1. CUERDA ARNAU, M.L. "Agresión y abuso sexual: Violencia o intimidación vs. Consentimiento viciado» en FARALDO CABANA, P y ACALE SÁNCHEZ, M (Dirs.). La Manada. Un antes y un después... op. cit., p. 112. GAVILÁN RUBIO, M. «Agresión sexual y abuso con prevalimiento »op. cit., p. 90.

${ }_{98}$ STS n $^{\circ} .511 / 2007$, de 7 de junio, F. j. 4 y STS no. 573/2017, de 18 de julio, F. j. 6.

99 DE VICENTE MARTÍNEZ, R. «El delito de violación » op. cit., p. 185 
agresiones sexuales la jurisprudencia ha venido configurando una conceptualización más detallada. Así, la intimidación del Art. 178 del Código Penal viene definida como el «constreñimiento psicológico, consistente en la amenaza o el anuncio de un mal grave, futuro y verosímil, si la víctima no accede a participar en una determinada acción sexual» ${ }^{100}$. Dicho mal no ha de ser necesariamente inmediato ${ }^{101}$ pero sí injusto y determinado ${ }^{102}$. Asimismo, la jurisprudencia viene requiriendo que la intimidación sea «seria, previa, inmediata, grave y determinante del consentimiento forzado» ${ }^{103}$, además, según las circunstancias concretas, ha de ser bastante o suficiente para someter o suprimir la voluntad de resistencia de la víctima ${ }^{104}$, sin tener que llegar a ser de tal grado que resulte irresistible para ella ${ }^{105}$. Sin embargo, en aras de detallar la idoneidad objetiva de la intimidación en la agresión sexual, la jurisprudencia y la doctrina han ido precisando de algunas aclaraciones que resultan determinantes.

En primer lugar, resulta esencial atender a las circunstancias específicas que concurren en cada caso. La línea jurisprudencial mayoritaria observa que, dentro de aquella, además de tener en cuenta el plano subjetivo, esto es, las circunstancias personales del sujeto pasivo, resulta fundamental observar las características objetivas de la conducta llevada a cabo por el sujeto activo $^{106}$ y las circunstancias que la envuelven ${ }^{107}$. En contraposición, también

100 SAP de Navarra, $n^{\circ}$. 38/2018, de 20 de marzo, F. j. 4.

${ }^{101}$ Entre otras, STS no. 914/2008, de 22 de diciembre, F. j. 5 y STS nº 9/2016, de 21 de enero, F. j. 1.

102 STS nº. 593/2003, de 16 de abril, F. j. 2 y STS n ${ }^{\circ} .1875 / 2002$, de 14 de febrero de 2003, F. j. 4. Se discute, más adelante, en el apartado «Una sutil línea divisoria» la necesidad de que el mal esté determinado, pues se cuestiona que la intimidación no pueda darse cuando existe amenaza de un mal no concretado.

103 STS n $^{\circ}$. 9/2016, de 21 de enero, F. j. 1; SAP Navarra $n^{\circ}$. 38/2018, de 20 de marzo, F. j. 4; GAVILÁN RUBIO, M. «Agresión sexual y abuso con prevalimiento » op. cit., p. 90 y DE VICENTE MARTÍNEZ, R. «El delito de violación » op. cit., p. 186. El mal no ha de ser inmediato pero la intimidación «ha de preceder inmediatamente al acceso carnal y encaminarse a conseguirlo» ATS $n^{\circ}$. 2333/2009, de 13 octubre, F. j. 3.

${ }^{104}$ Entre otras, STS no. 9/2016, de 21 de enero, F. j. 1 y STS no. 609/2013, de 10 de julio, F. j. 10; STS n ${ }^{\circ}$. 1689/2003, de 18 de diciembre, F. j. 2.

105 Entre otras muchas, STS n ${ }^{\circ}$ rec. 3083/1999, de 10 de julio de 2001, F. j. 3; STS nº. 1689/2003, de 18 diciembre, F. j. 3; STS nº. 609/2013, de 10 de julio, F. j. 10; STS nº. $355 / 2015$, de 28 de mayo, F. j. 13. Al igual que en el caso de la agresión sexual en la que media violencia, como ya se ha comentado.

106 STS n ${ }^{\circ}$. 609/2013, de 10 de julio, F. j. 10: «Lo relevante es el contenido de la acción intimidatoria llevada a cabo por el sujeto activo más que la reacción de la víctima frente a aquélla. El miedo es una condición subjetiva que no puede transformar en intimidatoria una acción que en sí misma no tiene ese alcance objetivamente».

107 DE VICENTE MARTÍNEZ, R. «El delito de violación » op. cit., p. 186 y 187 
existen ejemplos (aunque escasos) del TS en los que se afirma que «resulta más relevante el aspecto subjetivo» pues a pesar de existir «un mínimo de entidad objetiva» lo verdaderamente determinante es «la forma en que la misma ha sido vivenciada por la víctima» ${ }^{108}$. En cualquier caso, para la concurrencia de intimidación ambos planos han de ser analizados por perspectivas razonables para un observador neutral que concluya que «la víctima alcanza razonablemente el convencimiento de la inutilidad de prolongar una oposición de la que podrían derivarse mayores males, implícita o expresamente amenazados por el autor, accediendo forzadamente a las pretensiones de este ${ }^{109}$. Consecuentemente, circunstancias como la asimetría derivada de la diferencia de edades entre víctima y agresor, el lugar de los hechos, la situación de vulnerabilidad de la víctima y la imposibilidad de huida, entre otras, en relación con las características del dolo del atacante, gozan de gran relevancia en la calificación jurídica, resultando determinantes.

Asimismo, se requiere la existencia de una vinculación causal entre la intimidación ejercida y el contacto sexual alcanzado, que no se habría alcanzado si no mediara aquella ${ }^{110}$. La determinada conducta ha de estar dirigida por el sujeto activo a alcanzar el fin ilícito propuesto del acto sexual de modo que, inhibiendo la voluntad de resistencia por convencimiento de la inutilidad de continuar la oposición que podría derivar en un mal mayor, y actuando en adecuada relación causal, la intimidación esté conectada, de medio a fin, con el acto de contenido sexual ${ }^{111}$.

Por otro lado, como afirma CARUSO FONTÁN, existe la posibilidad de concurrencia de intimidación cuando la amenaza no contiene un mal concreto ${ }^{112}$. Se trata de la figura jurisprudencial de la «intimidación ambiental», que no está expresamente prevista en los delitos de agresión o abuso sexual en el Código pero que el TS viene aplicando. Esta se define como la «forma de amedrentamiento que, con independencia de cuál de los procesados fuese quien materialmente emplease los mecanismos físicos o psíquicos productores de terror en la víctima, se produce por el hecho de que los demás acompañantes están presentes ${ }^{113}$. De este modo, el efecto intimidatorio puede existir por la simple presencia de un grupo de personas distintas del que consuma materialmente pero

${ }^{108}$ STS n $^{\circ} .1366 / 1999$, de 1 de octubre, F. j. 1.

109 DE VICENTE MARTÍNEZ, R. «El delito de violación » op. cit., p. 186.

110 RAMON RIBAS, E. «El concepto de intimidación en los delitos de agresiones sexuales. Comentario de la STS 1396/1999, de octubre (RJ 1999,7597)». Revista de derecho y proceso penal, $\mathrm{N}^{\circ} .10,2003$, p. 266.

${ }_{111}$ STS no ${ }^{\circ} .914 / 2018$, de 22 de diciembre, F. j. 5 y STS no . 609/2013, de 10 de julio, F. j. 10, STS no rec. 2205/1999, de 24 de mayo de 2001, F. j. 5.

112 CARUSO FONTÁN, M. V. Nuevas perspectivas sobre los delitos contra la libertad sexual. Valencia: Ed. Tirant lo Blanch, 2006, p. 190.

${ }_{113}$ STS n $^{\circ}$ rec. 507/1996, de 3 de octubre de 1997, F. j. 1. 
que se convierten en cooperadores necesarios ${ }^{114}$, y su consciencia del ataque sexual, que contribuyen en el ambiente intimidatorio y refuerzan la posición de desamparo de la víctima ${ }^{115}$. No obstante, la jurisprudencia ha señalado que esta figura no se observa para la calificación de una agresión sexual, sino en sede de la autoría para deducir la cooperación necesaria ${ }^{116} \mathrm{y}$ afirma que se requiere una acción objetivamente constatable «pues no existe por la sola vulnerabilidad» ${ }^{117}$, además en su modalidad tácita se requiere un plan preconcebido o premeditado y el acaecimiento de sucesos previamente concertados ${ }^{118}$.

La jurisprudencia y la doctrina también han ido evolucionando y razonando en torno a la figura de la resistencia. Como se ha comentado, no se exige que la intimidación sea irresistible. No obstante, a pesar de que la jurisprudencia actual rechaza la antigua resistencia heroica que se le exigía a la mujer ${ }^{119}$, en ocasiones la interpretación tan restrictiva de la intimidación se acerca a ella ${ }^{120}$. Asimismo, todavía hoy en día la mayoría de la doctrina atribuye a la resistencia la calificación de elemento típico en la agresión sexual, lo que GONZÁLEZ RUS critica, pues esta cualificación favorece que los tribunales deduzcan que su ausencia es equivalente al consentimiento ${ }^{121}$. Comparte este pensamiento CUERDA ARNAU que añade que la resistencia se trata de un mero «indicio probatorio más de la falta de consentimiento, lo cual puede probarse de modos distintos al de ofrecer resistencia» ${ }^{122}$.

Finalmente, el máximo tribunal aclaró que para la concurrencia de una agresión intimidatoria el sujeto activo no tiene que ser consciente del estado psicológico de la víctima durante el transcurso de los hechos, siendo suficiente que este sepa que se trata de un contexto intimidante para ella ${ }^{123}$.

${ }^{114} \operatorname{STS~n}^{\mathrm{o}} .786 / 2017$, de 30 de noviembre, F. j. 3 y STS no ${ }^{\circ}$ 1291/2005, de 8 de noviembre, F. j. 2. 82.

115 ACALE SANCHEZ, M. «Tratamiento penal de la violencia sexual...» op. cit., p.

116 STSJ de Navarra $n^{\circ} .8 / 2018$, de 30 de noviembre, F. j. 17.

117 STS n ${ }^{\circ} .1458 / 2002$, de 17 de septiembre, F. j. 1.

118 Siendo estos sucesos simplemente aprovechados se estaría en el abuso con prevalimiento. STSJ de Navarra $n^{\circ} .8 / 2018$, de 30 de noviembre, F. j. 17.

119 A esta resistencia hacen referencia la STS 28/2/1974 (R.A 88) y la STS 6/61972 (R.A. 2988) que aprecian la «resistencia seria y constante de la mujer atacada que tenaz y firmemente luchó a costa de su integridad física» tomado de CUGAT, M. «La ambivalencia » op. cit., p. 77.

120 SUAY HERNANDEZ, B. C. «Ausencia de consentimiento e intimidación en el delito de violación (Comentario a la STS de 16 de enero de 1991. El caso del «alfiler»)». La Ley: Revista jurídica española, $\mathrm{N}^{\mathrm{o}} 1,1992$, p. 1062

${ }^{121}$ CUERDA ARNAU, M.L. «Agresión y abuso sexual » op. cit., p. 113.

122 Ibidem, p. 114

123 ACALE SANCHEZ, M. «Ser o no ser (de La Manada): esta es la cuestión». Nueva Tribuna, 2018, disponible en https://www.nuevatribuna.es/articulo/sociedad/ser-ser-ma- 


\subsection{El prevalimiento en los abusos sexuales con acceso carnal}

En aras de entender este elemento típico, resulta imprescindible acudir a la disposición 181.1 de nuestro Código Penal para observar que el abuso sexual acaece cuando se ataca la libertad o indemnidad sexual de una persona «sin violencia o intimidación, y sin que medie consentimiento». Sin embargo, el propio texto contempla para este mismo delito la posibilidad de obtener el consentimiento «prevaliéndose el responsable de una situación de superioridad manifiesta que coarte la libertad de la víctima» (Art. 181.3), se trata del abuso sexual con prevalimiento. El tipo agravado que recoge el acceso carnal se halla en el siguiente párrafo, el 181.4. Consecuentemente, en el abuso por prevalimiento es posible identificar dos elementos, uno negativo que consiste en la ausencia de violencia o intimidación, y otro positivo que se trata de la existencia del consentimiento, que obviamente se encuentra viciado (lo que diferencia al prevalimiento del resto de modalidades de abuso sexual en las que la víctima no tiene la ocasión de manifestar su voluntad o su consentimiento no es trascendente ${ }^{124}$ ).

Para la generalidad de la jurisprudencia y la doctrina académica, resulta determinante en el abuso sexual por prevalimiento que, aunque su voluntad se encuentra coartada, el sujeto pasivo se preste al acto sexual concreto. Así, el TS ha descrito reiteradamente el prevalimiento como el modus operandi a través del cual, ante un supuesto de «desnivel notorio» entre las posiciones de las partes, el agente se aprovecha de una situación de superioridad manifiesta para coartar la libertad de la víctima y obtener así su consentimiento, viciado. ${ }^{125}$ Esto es, existe un consentimiento viciado debido a que el atacante, aprovechándose de las circunstancias, interviene en el proceso de formación de la voluntad del sujeto pasivo haciendo que esta se configure de acuerdo a las apetencias del primero ${ }^{126}$. De este modo, para que el abuso sexual por prevalimiento se produzca, la jurisprudencia exige tres requisitos: « $1^{\circ}$ ) Situación

nada-es-cuestion/20180428190127151339.html

${ }^{124}$ MUÑOZ CONDE, F. y LÓPEZ PEREGRÍN, C. Derecho penal. Parte especial, $21^{\text {a }}$ Edición, Valencia: Ed. Tirant lo Blanch, 2017, p. 207 y CUERDA ARNAU, M. L. «Agresión y abuso sexual » op. cit., p. 127.

${ }_{125}$ Entre otras muchas, STS n ${ }^{\circ} .630 / 2016$, de 14 de julio, F. j. 6; STS no 935/2005, de 15 de julio, F. j. 5; STS no . 512/2013, de 13 de junio, F. j. 1. También puntualiza la jurisprudencia que la relación de superioridad del sujeto activo respecto a la vista puede ser constatada de forma objetiva, mientras que el aprovechamiento de esa situación «ha de ser inferido de forma racional por el órgano jurisdiccional» STS $n^{\circ} .1165 / 2003$, de 18 de septiembre, F. j. 10; STS n ${ }^{\circ}$. 785/2007, de 3 de octubre, F. j. 4; STS nº 834/2014, de 10 de diciembre, F. j. 3.

126 STS nº. 935/2006, de 2 de Octubre, F. j. 1; STS nº. 937/2000 de 26 de mayo, F. j. 1 y RAMON RIBAS, E. «El concepto de intimidación»op. cit., p. 268 y GAVILÁN RUBIO, M. «Agresión sexual y abuso con prevalimiento » op. cit., p. 86. 
de superioridad, que ha de ser manifiesta. $2^{\circ}$ ) Que esa situación influya, coartándola, en la libertad de la víctima. $3^{\circ}$ ) Que el agente del hecho, consciente de la situación de superioridad y de sus efectos inhibidores de la libertad de decisión de la víctima, se prevalga de la misma situación para conseguir el consentimiento, así viciado, a la relación sexual» ${ }^{127}$.

Como se comentaba en líneas anteriores, en una interpretación sistemática del Código la ausencia de violencia o intimidación resulta esencial a la hora de diferenciar los abusos de las agresiones sexuales. No obstante, existe una línea doctrinal que defiende la posibilidad de concurrencia de una intimidación «de segundo grado» compatible con los abusos sexuales por prevalimiento, que no alcanza la gravedad ni la intensidad exigidas en las agresiones sexuales ${ }^{128}$. En esta misma línea han aplicado el tipo los tribunales ${ }^{129}$, de modo que su propósito original ha quedado algo desvirtuado: la jurisprudencia incluye en el abuso sexual con prevalimiento las conductas en las que no existe una situación de superioridad previa ${ }^{130}$ de la que el sujeto activo se prevale para conseguir el consentimiento que no habría logrado de otra manera, que era la aspiración inicial del tipo, sino que se da un contexto intimidatorio que permite que el atacante no necesite proferir amenazas concretas para que

127 Entre otras muchas, STS n ${ }^{\circ} .1518 / 2001$, de 14 de septiembre, F. j. único; STS no . 834/2014, de 10 de diciembre, F. j. 3; STS n ${ }^{\circ}$. 9/2016, de 21 de enero, F. j. 1; STS $n^{\circ}$. 305/2013, de 12 de abril, F. j. 3 y STS n ${ }^{\circ}$ 935/2005, de 15 de julio, F. j. 5. En este segundo requisito hace hincapié FARALDO, P. «¿Intimidación o prevalimiento? La sentencia de La Manada y los delitos sexuales en España». Criminal Justice Network, 2018: «La posición de superioridad ha de ser suficientemente relevante como para coartar en el caso concreto la libertad del sujeto pasivo» disponible en http://www.criminaljusticenetwork. eu/es/post/intimidacion-o-prevalimiento-la-sentencia-de-la-manada-y-los-delitos-sexuales-en-espana

${ }^{128}$ CUERDA ARNAU, M.L. «Agresión y abuso sexual » op. cit., p. 124 y 125. A modo de ejemplo, siguen esta línea MORALES PRATS, F. y GARCÍA ALBERO, R. M, «Título VIII. Delitos contra la libertad e indemnidad sexuales», en Comentarios al Nuevo Código Penal, Navarra: Ed. Cizur Menor, 2016, p. 1269 - 1405 y FARALDO, P. «¿Intimidación o prevalimiento?...« op. cit.

${ }^{129}$ Entre otras, STS nº. 542/2013, de 20 de mayo, F. j. 5: «En el prevalimiento, la situación que coarta la libertad de decisión es una especie de intimidación pero de grado inferior»».

${ }^{130}$ El artículo 181.3 no limita las causas originarias de la situación de superioridad, que puede deberse a circunstancias como la diferencia de edad entre la víctima y el sujeto activo (STS n'. 724/2018, de 24 de enero, F. j. 1), sus lazos de parentesco (STS n ${ }^{\circ}$. 203/2013, de 7 de marzo, F. j. 1), las relaciones de poder real, de tipo moral, de carácter reverencial, laborales o económicas (STS n ${ }^{\circ}$ Rec. 687/1991, de 8 de febrero, F. j. 1), entre otras. En este sentido, MORALES PRATS, F y GARCÍA ALBERO, R. «Título VIII » op. cit., p. 1308 apuntan que la superioridad manifiesta puede existir en aquellas situaciones en las que se evidencia una «asimetría de poder» entre sujeto activo y sujeto pasivo. 
la víctima se someta a los actos sexuales por encontrarse en inferioridad de condiciones $^{131}$.

\section{3. «Una sutil línea divisoria» ${ }^{132}$}

En un primer lugar, la diferenciación de ambas figuras parece clara: cuando se actúa con violencia o intimidación y contra el consentimiento de la víctima concurre la agresión, y si el acto se ejecuta sin y sin el consentimiento concurre abuso sexual ${ }^{133}$. Sin embargo, como se ha comentado previamente, la dificultad aparece al discernir si se está ante los abusos sexuales con prevalimiento o las agresiones sexuales intimidatorias, pues son figuras extremadamente próximas. De hecho, el TS ha apreciado en varias ocasiones este conflicto: «la línea divisoria entre la intimidación y el prevalimiento puede ser difícilmente perceptible en los casos límite como lo es la diferencia entre un consentimiento cercenado por la amenaza de un mal y el viciado que responde al tipo del abuso, donde la víctima en alguna medida también se siente intimidada ${ }^{134}$. La

${ }^{131}$ FARALDO CABANA, P. y RAMON RIBAS, E. «La sentencia de La Manada...» op. cit., p. 291 y 293. En este mismo sentido, señala ASUA, A. «Las agresiones sexuales » op.cit., p. 24 que mediante la tipificación del abuso sexual con prevalimiento, se cubren las situaciones en las que el sujeto activo no tiene que acudir a la intimidación y, para lograr que la víctima acceda a los actos sexuales, recurre a otro tipo de presiones mediante las cuales constriñe la libertad de la víctima desde una situación ventajosa. La misma añade que con esta figura de abuso sexual por prevalimiento se cubren situaciones fronterizas a la violación que anteriormente derivaban en la absolución por dificultades de determinación del grado de constricción de la voluntad de la víctima. Existen ciertos autores como CUERDA ARNAU, M.L. "Agresión y abuso sexual » op. cit., p. 126 que niegan la existencia de una intimidación en el abuso sexual de prevalimiento: «Y es que si se repara en la referida tesis, se advertirá que lo que de ella se desprende es que hay intimidaciones que conceden al intimidado la posibilidad de elegir, lo que trasladado al ámbito de la violencia podría conducir a sostener que, salvo en casos de inusitada violencia, el sujeto pasivo tiene la posibilidad de elegir entre soportar la violencia o el acto que se le impone»

${ }^{132}$ Expresión utilizada por STS $n^{\circ}$. 769/2015, de 15 de diciembre, F. j. 8; STSJ de Navarra $n^{\circ} .8 / 2018$ de 30 de noviembre, F. j. 15 y STS n ${ }^{\circ} .1030 / 2010$, de 2 de diciembre, F. j. 3 para referirse a la proximidad entre la intimidación de la agresión sexual y el abuso sexual por prevalimiento

133 CADENA SERRANO, F. A. «Tipos agravados en los delitos de agresión sexual del artículo $178 \mathrm{CP}$ y del artículo $179 \mathrm{CP}$ problemas de autoría, participación, comisión por omisión y concursos en el delito de Violación». Cursos de formación del Ministerio Fiscal, 2014 disponible en https://www.fiscal.es/fiscal/PA_WebApp_SGNTJ_NFIS/descarga/Ponencia_Fidel\%20Angel\%20Cadena\%20Serrano.pdf?idFile=e78ac331-d98e-4509-b0186fea52ae7c87 y CUERDA ARNAU, M.L. «Agresión y abuso sexual » op. cit., p. 129

134 STS n $^{\circ}$. 1030/2010, de 2 de diciembre, F. j. 3; STS no. 769/2015, de 15 diciembre, F. j. 8; STSJ de Navarra n $^{\circ} .8 / 2018$, de 30 de noviembre, F. j. 15 y STS nº $.935 / 2006$, de 2 de octubre, F. j. 10. 
misma sala ha tratado en reiteradas ocasiones arrojar luz sobre este asunto manifestando que la diferencia entre ambos radica en que en la intimidación de la agresión sexual el ataque vence la voluntad contraria de la víctima, mientras que en el abuso por prevalimiento el ataque tiene como resultado el vicio en el consentimiento del sujeto pasivo ${ }^{135}$. No obstante, no parece que esta cuestión esté solventada. Es más, recientemente, con el notorio caso de La manada en el que dos de los magistrados del TSJ de Navarra observaron agresión sexual intimidatoria y tres de ellos se decantaron por el abuso sexual con prevalimiento, esta distinción que ya suscitaba debate se ha convertido en el objeto central de intensa reflexión doctrinal ${ }^{136}$, que incluso ha derivado en distintos planteamientos de una reforma del código ${ }^{137}$. Esto se debe a que el fino linde, además de en consecuencias penológicas dispares ${ }^{138}$, deriva en distintas calificaciones jurídicas de los hechos, siendo estas últimas las verdaderamente trascendentales en el presente trabajo.

El primer inconveniente en esta distinción se halla en que el carácter subjetivo resulta determinante en estos delitos, cuya apreciación suele resultar compleja y de laboriosa percepción, como lo puede ser la determinación del grado de constreñimiento de la voluntad de la víctima ${ }^{139}$. En segundo lugar, la legislación actual que trata este asunto es teóricamente clara pero en la práctica resulta tremendamente compleja de modo que, basándose en la ley,

$135 \mathrm{STS} \mathrm{n}^{\mathrm{o}}$ rec. $817 / 2000$, de 25 de junio de 2001, F. j. 2.

136 STSJ de Navarra $n^{\circ} .8 / 2018$, de 30 de noviembre.

137 Proposición de Ley de Protección Integral de la Libertad Sexual y para la erradicación de las violencias sexuales planteada por el Grupo Parlamentario Confederal de Unidos Podemos-En Comú Podem-En Marea. Boletín Oficial de las Cortes Generales. Congreso de los Diputados. XII Legislatura. Serie B: Proposiciones de Ley, núm. 297-1, de 20 de julio de 2018. Además, diversos autores de la academia como ACALE SANCHEZ, M. Ser o no ser... op. cit., y LASCURAÍN, J.A. «QQué es una violación?». Criminal Justice Network, 2018, disponible en http://www.criminaljusticenetwork.eu/es/post/ que-es-una-violacion también han observado, la necesidad de una reforma del código en torno a este asunto, aunque sus planteamientos son dispares.

${ }_{138}$ El marco punitivo para el acceso carnal en el caso de la agresión sexual es de 6 a 12 años de prisión, mientras que en relación al abuso sexual es de 4 a 10 años. La distancia aparece más amplia cuando concurren agravantes, que son compartidos por ambos tipos en el caso de que la víctima sea menor de dieciséis años pero no si se trata de un sujeto pasivo mayor de dicha edad. Es más, resulta digno de atención el hecho de que el agravante de «actuación conjunta de dos o más personas» en víctimas mayores de 16 años sólo se contempla para la agresión sexual.

139 LASCURAIN, J. A. «Las Huellas de la Manada». Almacén de derecho, 2018, disponible en https://almacendederecho.org/las-huellas-la-manada/. Además asentada jurisprudencia señala que «para delimitar dicho condicionamiento típico debe acudirse al conjunto de circunstancias del caso concreto que descubra la voluntad opuesta al acto sexual» STS nº 1030/2010, de 2 de Diciembre, F. j. 3. 
se pueden tomar dos caminos de manera que los mismos hechos probados podrían llevar a soluciones dispares, estando ambas adecuadamente fundamentadas $^{140}$. Consecuentemente, de algún modo se podría poner en riesgo la seguridad jurídica.

Sin embargo, la verdadera complicación en la distinción se da sobre la base de la concurrencia de intimidación en el abuso sexual con prevalimiento, que no alcanza la intimidación requerida en las agresiones sexuales. Es más, para RAMON RIBAS la intimidación y el prevalimiento son estructuralmente idénticas, pues además de que ambas presentan la intimidación originada por el anuncio expreso o tácito de causar un mal, también en las dos concurre una situación de superioridad manifiesta de la que se prevale el atacante, a pesar de que en el caso de la agresión la situación es creada por la propia intimidación ${ }^{141}$. Sin embargo, observa el autor diferencias cuantitativas en el grado de incidencia de la intimidación, que derivan en distintas limitaciones a la libertad, pudiendo verse esta anulada o, en caso de menos entidad, coartada ${ }^{142}$. El propio Art. 181.3 dispone que el prevalimiento concurre cuando "se coarte la libertad de la víctima», de este modo se puede inferir que si la libertad se encuentra totalmente anulada por una intimidación, estaremos ante el tipo de las agresiones sexuales intimidatorias ${ }^{143}$.

Siguiendo esta línea, autores como FARALDO CABANA y RAMON RIBAS relacionan esta naturaleza intensa de la intimidación en las agresiones sexuales con la concurrencia de amenazas concretas, mientras que la intimidación que acaece en los abusos se vincula con una atmósfera de temor ${ }^{144}$. En este sentido, el segundo de los autores afirma que la expresión «bastante», explicada anteriormente en este capítulo, que la jurisprudencia identifica con la intimidación de la agresión sexual, ha de interpretarse en un doble sentido: además de referirse a la suficiencia para suprimir la voluntad de resistencia de la víctima que señalan los tribunales (esta adecuación también debe darse

${ }^{140}$ De hecho, se trata del caso comentado previamente respecto a los magistrados del TSJ de Navarra. FARALDO, P. «Las relaciones sexuales son espontáneas y nadie quiere regularlas». El Ideal Gallego, 2018 disponible en https://www.elidealgallego.com/articulo/coruna/patricia-faraldo-relaciones-sexuales-son-espontaneas-nadie-quiere-regularlas/20180713220853378486.html.

${ }^{141}$ RAMON RIBAS, E. «La intimidación en los delitos sexuales...» op. cit., p. 144.

142 Ibidem, p. 145.

${ }^{143}$ MORALES PRATS, F. y GARCÍA ALBERO, R. «Título VIII » op. cit., p. 313 y CUERDA ARNAU, M.L. «Agresión y abuso sexual » op. cit., p. 127.

${ }^{144}$ FARALDO CABANA, P. y RAMON RIBAS, E. «La sentencia de La Manada...» op. cit., p. 293. Además para RAMON RIBAS, E. «El concepto de intimidación » op. cit., p. 268 las agresiones responden a una conducta impuesta mientras que el abuso con prevalimiento se trata de la intervención en el proceso de formación de la víctima para que se lleve a cabo o se soporte la conducta. 
en el prevalimiento, que ha de ser apto para influir en el comportamiento sexual de la víctima), ha de entenderse como «bastante» para conceptuarse como agresión sexual ${ }^{145}$. Esto es, también debe la lesión de la libertad poder calificarse como una agresión, pues ha de ser «un ataque específicamente cualificado a aquella de intensidad superior al inherente a los abusos sexuales ${ }^{146}$. Por tanto, al comportar el abuso sexual con prevalimiento cierta lesión de libertad (intimidación de segundo grado), la intimidación de la agresión «debe incorporar una dimensión que la permita distinguirla» de dicho ataque menos grave ${ }^{147}$. Así, continúa el autor, para determinar si la intimidación es suficiente en este segundo sentido, será necesario «incorporar elementos de distinción entre intimidaciones constitutivas de abuso y las conceptuales como agresión ${ }^{148}$. En concordancia con él, BOIX REIG y ORTS BERENGUER ${ }^{149}$ discurren sobre esta cuestión para razonar que la intimidación se enmarca en las agresiones sexuales cuando esta es tal que la conducta de la víctima se observa como impuesta u obligada, lo que no ocurre en el abuso por prevalimiento, en el que la entidad de la intimidación permite actuar con cierta libertad condicionada. Así, RAMON RIBAS concluye descartar «la automática subsunción de cualquier género de intimidación en los tipos de agresiones sexuales» ${ }^{150}$, pues el delito de agresión sexual requiere una intimidación de cierta entidad objetiva ${ }^{151}$, y por ello, y pese a la redacción del Código («sin violencia o intimidación»), la concurrencia de intimidación no descartará automáticamente el tipo del abuso sexual. De estas reflexiones se puede colegir que la mayor dificultad en la distinción se encontrará en la entidad de la intimidación, concretamente a la hora de analizar una conducta

${ }^{145}$ RAMON RIBAS, E., «El concepto de intimidación » op. cit., p. 269. En contraposición, la autora CUERDA ARNAU, M.L. «Agresión y abuso sexual » op. cit., p. 126 rechaza esta teoría sosteniendo que si la intimidación se ha acreditado suficiente para doblegar la voluntad de la víctima nada más se requiere para concluir que se está ante una agresión sexual.

146 RAMON RIBAS, E. «El concepto de intimidación » op. cit., p. 267

147 Ibidem.

148 Ibídem, p. 268. Esta misma dirección parece seguir la jurisprudencia, que hace hincapié en la gravedad de la intimidación que requiere la agresión, de modo que si no reviste ese alcance no ha de incorporarse en dicha modalidad de ataque debiendo integrarse en los abusos sexuales (STS n ${ }^{\circ}$. 409/2000, de 13 de marzo, F. j. 3)

149 BOIX REIG, J. y ORTS BERENGUER, E. «Consideraciones sobre la reforma de los delitos contra la libertad sexual, por la Ley Orgánica 11/1999» en QUINTERO OLIVARES, G. y MORALES PRATS, F. (Coords.). El nuevo Derecho Penal español. Navarra: Ed. Cizur Menor, 2001, p. 1019, que señalan que en el abuso sexual con prevalimiento se actúa con cierta libertad condicionada que no existe en la agresión sexual y RAMON RIBAS, E. «La intimidación en los delitos sexuales »op. cit., p. 146.

${ }^{150}$ RAMON RIBAS, E. «El concepto de intimidación » op. cit., p. 269

151 STS n ${ }^{\circ} .1396 / 1999$, de 1 de octubre, F.j. 1. 
típica que presente el elemento de intimidación pero resulte dudoso si esta es suficiente para anular la voluntad de la víctima de modo que no tenga más opción que soportar el acto sexual o no ${ }^{152}$, pues lo determinante es la capacidad de la intimidación para el constreñimiento de la libertad del sujeto pasivo.

En aras de colaborar en la distinción, el TS ha señalado mediante reiterada jurisprudencia que la intimidación de la agresión supone la presentación de un mal, identificado y de posible realización ${ }^{153}$. No obstante, el mismo tribunal también llegó a considerar la concurrencia de este delito argumentando: «no aparece acto alguno de fuerza física para conseguir los mencionados accesos carnales, y no existió amenaza de un mal concreto. Pero todo, desde el comienzo, se desarrolló en un ambiente de intimidación que produjo miedo en la víctima, y esto fue la causa de que ella no se resistiera e incluso que colaborara $\rangle^{154}$. Por este motivo no se entiende fácilmente que el TSJ de Navarra señale en el caso de La Manada que «el bloqueo psicológico» que le imposibilitaba pensar y reaccionar a la víctima no sea constitutivo de intimidación y, por tanto, ha de calificarse como abuso ${ }^{155}$. Sin embargo, corrigiendo el error de calificación jurídica en el que, estima el TS, el TSJ (así como la AP de Navarra ${ }^{156}$ ) incurrió, el máximo tribunal falló el pasado 21 de junio la concurrencia de un delito continuado de violación ${ }^{157}$, lo que consolida su jurisprudencia y se espera genere, por su notoriedad, un efecto general de prevención. Se trata de un momento remarcable en la jurisprudencia de los delitos sexuales en España.

${ }^{152}$ STS n $^{\text {o. }}$ 542/2013, 20 de mayo, F. j. 5: «La intimidación que caracteriza al delito de agresión sexual, en el que el sujeto pasivo no puede decidir». Para RAMON RIBAS, E. «La intimidación en los delitos sexuales » op. cit., p. 143 si la víctima conserva la opción de negarse al acto existe abuso sexual. De este modo, se entiende que en los abusos por prevalimiento la víctima ve lesionada su libertad de decidir, mientras que en la agresión lo que se menoscaba es la libertad de obrar FARALDO CABANA, P. y RAMON RIBAS, E. «La sentencia de La Manada » op. cit., p. 258 y 259

${ }_{153}$ STS n $^{\text {o. }}$ 132/2016, de 23 de febrero, F. j. 2 y STS n ${ }^{\circ}$. 9/2016, de 21 de enero, F. j. 1.

${ }^{154}$ STS n n $^{\circ}$. 744/2004, de 14 junio, F. j. 3.

155 STSJ de Navarra $\mathrm{n}^{\circ} .38 / 2018$, de 30 de noviembre.

156 SAP de Navarra, $n^{\circ} .38 / 2018$, de 20 de marzo.

${ }^{157}$ Sostiene el TS que «el relato factico describe un auténtico escenario intimidatorio, en el que la víctima en ningún momento consiente a los actos sexuales». Fallo del TS $\mathrm{N}^{\mathrm{o}}$ Rec. 396/2019 de 21 de junio disponible en http://www.poderjudicial.es/cgpj/es/PoderJudicial/Noticias-Judiciales/Comunicado-de-la-Sala-Segunda-del-Tribunal-Supremo-sobre-el-recurso-de-casacion-396-2019. No obstante, por razones temporales, no resulta posible indagar en los detalles exactos de la fundamentación jurídica que han llevado al máximo tribunal a alcanzar esta decisión, pues la sentencia al completo todavía no es pública. 
Desdibujando aún más la línea divisoria que separa los dos tipos, en este sentido considera buena parte de la doctrina que para que la víctima se vea obligada a cometer el acto sexual no resulta preciso que se anuncie expresamente o comunique mediante gestos un mal concreto, pues se puede anunciar la posibilidad de un mal tácitamente (a través de las acciones, el sujeto activo, las circunstancias ). Esto se debe a que es posible atemorizar a la víctima (haciéndola entender la imposibilidad de protegerse ante una posible agresión y la ausencia de alternativas distintas del sometimiento) aunque esta desconozca las características exactas del mal que sufrirá ${ }^{158}$. Esto es, lo esencial será causar temor a la víctima y que el dolo del atacante abarque la voluntad de causar temor ${ }^{159}$, por tanto «esta situación podrá provocarse tanto mediante la amenaza de un mal concreto como mediante la creación de un ambiente intimidatorio» ${ }^{160}$.

Finalmente, la jurisprudencia también ha apuntado, al debatir entre intimidación o prevalimiento, que ante una muy fundada duda «debe resolverse a favor de reo» ${ }^{161}$. No obstante, esto conviene ser aplicado de manera cuidadosa, pues se puede dar el peligroso efecto de que, ante el conocimiento de casos complejos, se de cobijo en el abuso con prevalimiento a conductas que de no existir este tipo se enmarcarían ampliamente en la agresión sexual ${ }^{162}$. Asimismo, es importante subrayar que, en este punto conflictivo que reviste de tanta sutileza, los tribunales deben estar a las circunstancias específicas de cada caso concreto y evitar en la medida de lo posible posicionamientos tajantes que puedan restringir y limitar las sentencias que se dicten con

158 RAMON RIBAS, E. «La intimidación en los delitos sexuales » op. cit., p.161, 163 y 164

159 Tradicionalmente, la jurisprudencia exigía una intensidad del dolo concretado en un ánimo libidinoso, sin embargo, este requerimiento ha sido abandonado en la actualidad (STS n ${ }^{\circ}$. 132/2013, de 19 de febrero, F. j. 3). Sí se exige que el atacante conozca, por la naturaleza sexual del acto, que puede afectar la libertad o indemnidad sexual de la víctima (STS n ${ }^{\circ}$ 444/2007, de 8 de junio, F. j. 2)

${ }^{160}$ CARUSO FONTÁN, V., Nuevas perspectivas... op. cit, p. 186 - 188. Según el autor, esta interpretación coincide con la que la jurisprudencia ha mantenido tradicionalmente respecto al robo con intimidación, en el que el aspecto psicológico de la víctima es determinante. Asimismo, el autor destaca en este sentido la $33^{\text {a }}$ Ley de Modificación del Derecho penal alemán de 1 de julio de 1997 que equipara a la violencia y a la intimidación los casos de aprovechamiento de una situación en la cual la víctima, sin protección, está expuesta a las acciones del autor.

${ }_{161}$ STS n $^{\circ} 368 / 2010$, de 26 abril, F. j. 4.

162 En relación a esto, resulta fundamental abandonar definitivamente «las más que viejas concepciones que vinculaban la fuerza típica a la irresistibilidad de la misma y la intimidación al terror paralizante, dando paso a conceptos que miden los medios comisivos por su eficacia en el caso concreto para doblegar la voluntad de la víctima» CUERDA ARNAU, M.L. «Agresión y abuso sexual » op. cit., p. 104 y 107 
posterioridad ${ }^{163}$. Además, el papel de los tribunales resulta en este punto clave, pues ostentan la tarea de evitar que retrógradas ideas, que todavía se hallan en la sociedad, y que están dirigidas por pautas que arrinconan la libertad sexual de las mujeres y desvalorizan su comportamiento, se cuelen en la jurisprudencia y pervivan en ella.

\section{IV.VALORACIONES CRÍTICAS: REVISIÓN DEL CÓDIGO PENAL EN RAZÓN DE SUS DISFUNCIONALIDADES Y A LA LUZ DE LA NORMATIVA INTERNACIONAL.}

A raíz del presente análisis sobre algunos puntos conflictivos en la regulación del concepto de violación del Código Penal, realizado en conocimiento del desarrollo penal internacional y el marco legal europeo, es posible razonar la necesidad de una revisión y reformulación del Título VIII «Delitos contra la libertad e indemnidad sexuales» del Código.

Cabe destacar en primer lugar que la legislación y la jurisprudencia españolas han ido evolucionando en la misma dirección que los patrones que el panorama internacional ha desarrollado en relación a los delitos sexuales, y concretamente la violación, como la protección de la autonomía sexual o el rechazo a la exigencia de resistencia. No obstante, sí se aprecia discordancia entre la legislación española y los estándares legales internacionales que, desde principios del siglo XX, consolidan jurisprudencialmente la idea de que el actus reus de la violación es la ausencia de consentimiento ${ }^{164}$. La fuerza, por tanto, no se trata de un elemento sine qua non sino de uno de los varios que evidencian la falta de consentimiento, que es el elemento negativo determinante. Esta concepción todavía no ha sido adoptada por nuestro Código Penal. A nivel europeo, en concordancia con el Consejo de Europa, la legislación española también penaliza las relaciones sexuales sin consentimiento en las que no concurre violencia o intimidación (aunque sin apreciarlas como violación sino como abuso sexual y con consecuencias punitivas menos graves), y a pesar de no oponer resistencia la víctima ${ }^{165}$. No obstante, es claro que la legislación nacional no ha incorporado de manera completa el

163 ACALE SANCHEZ, M. «Ser o no ser...» op. cit. Pues como indica la STS no. 587/1998, de 28 de abril, F. j. 6 la fuerza o intimidación se manifiesta de muchas formas e intensidades en relación a la personalidad del sujeto pasivo, pues cada víctima responderá de maneras y magnitudes diferentes.

164 Sentencia del Tribunal Penal Internacional para la Antigua Yugoslavia de 22 de febrero de 2001, The prosecutor v. Dragoljub Kunarac, Radomir Kovac y Zoran Vukovic. No IT-96-23-T\& IT-96-23/1-A

165 Comité de Ministros del Consejo de Europa. Recomendación No. R (2002) 5 adoptada el 30 de abril de 2002 tomado de Amnistía Internacional. The right to be free... op . cit., p. 6. 
Convenio de Estambul ${ }^{166}$, en vigor en España desde el 1 de agosto de 2014. La implantación completa del tratado en la ley del país supondría dejar de lado la diferenciación en torno a los medios comisivos; a si el agente alcanzó el acceso carnal en contra de la voluntad de la víctima (agresiones sexuales violentas o intimidatorias), con su consentimiento viciado (abusos sexuales con prevalimiento) o sin él (abusos sexuales), pues todos estos casos se enmarcarían en actos sexuales no consentidos, que serían automáticamente calificados de violación. Se colige, por tanto, que nuestro código tampoco se ha adaptado al marco legal europeo.

El papel central que el Código Penal atribuye a los medios comisivos deriva en ciertos puntos conflictivos, pues el requerimiento de concurrencia de violencia o intimidación genera que algunos tipos de violaciones no se conceptualicen como tales, con los riesgos que esto conlleva: la generalidad de la sociedad, que se encuentra más o menos familiarizada con el concepto, muestra un rechazo amplio y creciente hacia el delito de violación (caso distinto es el de los abusos sexuales, con los que el imaginario social colectivo no es tan tajante ${ }^{167}$ ), por esta razón, las violaciones que penalmente no se califican como tal, podrían ser socialmente despojadas de su gran trascendencia y gravedad, colaborándose así en su normalización y baja concienciación. En este sentido, en la diferenciación entre la violación y el abuso sexual con acceso carnal, aparece el conflicto existente entre prevalimiento e intimidación. De este se colige que no hay una diferencia sustancial entre que sean las palabras o actos amenazantes los que constriñan psicológicamente la libertad de la víctima o que la que lo haga sea la situación de superioridad de la que el agente se aprovecha de modo que el empleo de dichas palabras o actos no son necesarios. En ambas circunstancias la víctima no actúa bajo su libre consentimiento, sino con su voluntad doblegada (de hecho, como se ha analizado, el sujeto pasivo del abuso por prevalimiento también podría encontrarse de algún modo intimidado). Por este mismo motivo, carece de sentido que la delgada línea que clasifica las conductas en el marco de las agresiones intimidatorias o en los abusos con prevalimiento se ensanche en materia de consecuencias penales, de modo que conductas con desvalor de acción y resultado sumamente similar se penalizan ${ }^{168}$ y conceptualizan de

${ }^{166}$ Como tampoco ha asumido la jurisprudencia del Tribunal Europeo de Derechos Humanos. Sentencia del Tribunal Europeo de Derechos Humanos de 4 de diciembre de 2003 No. 39279/98, (M.C. v Bulgaria), ECHR 2203XII

167 A modo de ejemplo, un estudio de The European Commission Eurobarometer mostró que el $27 \%$ de los participantes afirmaron que las relaciones sexuales sin consentimiento estaban justificadas en ciertas situaciones, como el caso de que la víctima esté ebria, bajo la influencia de las drogas, o si esta no se defiende. Amnistía Internacional. The right to be free... op. cit., p. 19.

168 Estas diferencias penológicas no son graves en relación al número exacto de años de prisión recogido en el Código, materia que el presente trabajo no valora, sino respecto 
manera muy distinta. Asimismo, tampoco parece muy congruente que el atacante que, por las circunstancias específicas, no haya tenido que proferir amenazas concretas, vea una extraordinaria reducción de su responsabilidad respecto del agente que no ha tenido la ocasión de prevalerse de dichas circunstancias.

Por otro lado, el consentimiento espurio del abuso con prevalimiento ha de interpretarse con sumo cuidado, pues cuando ante una situación de terror la víctima adopta una posición pasiva y resignada por encontrarse paralizada ante el ataque ${ }^{169}$, deducir que se trata de un consentimiento, siquiera viciado, supondría exigir a la víctima una resistencia activa, incluso heroica, que claramente la pone en peligro. Además, la paralización de la víctima podría hacer que el agente no necesitara emplear violencia ni intimidación de modo que no se cometería un delito de violación. Se concluye por tanto que es excesivo el peso que recae sobre la concurrencia o no de resistencia activa de la víctima.

Sin embargo, el límite que nuestro código observa para diferenciar la agresión del abuso sexual también ha de tenerse en consideración. Pues resulta lógica una respuesta penal diferente cuando varía la intensidad del constreñimiento psicológico ejercido sobre la víctima, para lo que se podrían plantear circunstancias agravantes ${ }^{170}$ (lo que además resulta acorde a lo dispuesto en el Artículo 46 del Convenio de Estambul). Consecuentemente, la concurrencia de dicha circunstancia supondría el aumento de una pena común, y la idéntica calificación jurídica otorgaría la misma significación y protección a la libertad sexual de todas las víctimas de accesos carnales no consentidos. De este modo, el mensaje que se enviaría a la sociedad, gracias al valor simbólico del sistema penal, consiste en que lo penalmente reprochable es actuar sin el consentimiento de la otra persona, esto es, no respetar su voluntad ni la manifestación de su libertad sexual individual. Colaborando así en la equiparación de la valoración social hacia todas las relaciones sexuales no consentidas.

Para la efectividad de esta reformulación, resulta imprescindible la introducción de la perspectiva de género en la actuación de todos los agentes que

a que una pena menor implica un mensaje de menor gravedad.

169 Un informe firmado por 1800 psicólogos sostiene que «ante una situación de amenaza de lesión grave o violencia sexual, es común una respuesta de inmovilización [ ], por tanto, no tiene sentido plantear la cuestión del consentimiento, ya que la capacidad estará anulada». Carta abierta de los/as profesionales de la psicología y la psiquiatría al Ministerio de Justicia y a la ciudadanía, 2018, Salud mental te cree, disponible en http://comunicadosaludmental.blogspot.de/2018/05/carta-abierta-de-losas-profesionales-de.html

170 Además, si las conductas violentas o intimidatorias suponen un especial atentado a la salud del sujeto pasivo, estas son contempladas específicamente a través del concurso de delitos, también el atentado contra la integridad moral. FARALDO CABANA, P. y RAMON RIBAS, E. «La sentencia de La Manada » op. cit., p. 257. 
aplican el Derecho, sobre todo de jueces y magistrados. Pues, como sostiene ASUA, «las normas jurídicas cobran vida a través de la recreación de los jueces, y no solo mediante las decisiones de absolución o condena, sino sobre todo a través de las explicaciones que motivan esas decisiones ${ }^{171}{ }^{17}$. Además, en incontables ocasiones la falta de esta perspectiva durante el enjuiciamiento ha derivado en la victimización secundaria del sujeto pasivo ${ }^{172}$, con la que es urgente acabar.

Por todo esto, se valora que la cuestión jurídica central en cuanto a la violación debe desplazarse de la concurrencia de violencia o intimidación hacia la falta de consentimiento, que debe ser el elemento definitorio del delito, poniéndose el énfasis en que la víctima no ha deseado el acceso carnal como resultado de su libertad sexual individual, que es el bien jurídico a proteger.

\section{CONCLUSIONES}

1. La tipificación de la violación a nivel global, delito que presenta un indudable sesgo de género marcado por el alto porcentaje de victimización de la mujer, se trata de un proceso que tradicionalmente se ha visto contaminado por imágenes patriarcales que todavía subsisten en la sociedad, haciendo que, a su vez, el sistema penal reproduzca estas ideas de discriminación hacia la mujer, en una retroalimentación constante. Sin embargo, se observa una relativamente reciente redirección y toma de conciencia en materia de igualdad en la normativa internacional, de la que la legislación española se ha nutrido.

2. No obstante, el Código penal español identifica la violación con la agresión sexual en la que concurre acceso carnal. De esta manera, para su calificación se precisa la existencia de violencia o intimidación, lo que contrapone de lleno los avances logrados por los estándares legales internacionales actuales, y más concretamente, por el tratado europeo denominado Convenio de Estambul que España ha ratificado. Esto se debe a que los anteriores vienen apreciando el delito de violación en torno a la falta de consentimiento de la víctima, que es el actus reus, independientemente de que concurra o no violencia o intimidación. El Código Penal español no se ha hecho eco de esta evolución y,

171 ASUA, A. «Las agresiones sexuales...» op. cit., p. 38.

172 Algunos ejemplos son la SAP de Pontevedra de 27 de febrero de 1989 en la que los acusados son absueltos por la «vida licenciosa» de la víctima y la SAP de Lérida de febrero de 1989 que enunció que la falda de la víctima provocó al agente, quien no pudo contenerse. Más recientemente, también resultó notoria la cuestión que en 2016 formuló la jueza a la víctima: «¿Cerró bien las piernas, cerró toda la parte de los órganos femeninos?» tomado de DE VICENTE MARTINEZ, R. «El delito de violación » op. cit., p. 212. 
por lo tanto, su tipificación del delito de violación se encuentra enranciada en comparación con los mecanismos legales internacionales.

3. Así, para la legislación española, cuando no se dan los medios comisivos concretos no concurre una violación, sino un delito de abuso sexual. En el límite existente entre las agresiones y los abusos sexuales, una muy estrecha línea separa ambas figuras situándose entre la agresión sexual intimidatoria y el abuso sexual con prevalimiento.

4. Esta frontera tan decisiva, resulta poco lógica entre conductas típicas muy semejantes. Pues, por lo que respecta al desvalor de acción, no existe una gran disparidad en que sean las palabras o actos amenazantes los que constriñan psicológicamente la libertad de la víctima o sea la situación de superioridad de la que el sujeto activo se aprovecha la que lo haga. En cuanto al desvalor de resultado, siendo cierto que el nivel de constreñimiento de libertad resulta mayor en la intimidación, ni en esta ni en el prevalimiento la víctima actúa bajo su libre consentimiento o bajo su voluntad derivada de su libertad sexual individual. No obstante, situarse a un lado u otro de dicha frontera supone consecuencias terminológicas muy importantes, como la consideración de violación o no.

5. Esta calificación jurídica juega un papel primordial que va mucho más allá de la simple función descriptiva, pues no denominar penalmente como violación algunas relaciones sexuales no consensuadas como consecuencia de la falta de acaecimiento de violencia o intimidación, supone desposeerlas de su relevancia y colaborar en su baja concienciación, infravalorando el valor que posee el consentimiento de la víctima por sí solo.

6. Consecuentemente, se colige urgente una reformulación del Título VIII Delitos contra la libertad e indemnidad sexuales que redefina el delito de violación, desplazando la línea decisiva que marca el límite del delito en los medios comisivos hacia la concurrencia del elemento negativo de ausencia de consentimiento. Reducir la violación a un tipo penal que tiene como objeto el acceso carnal no consensuado supondría la incorporación de la normativa internacional en relación a este delito. Además, esta nueva definición traería consigo derivaciones muy relevantes para la autonomía sexual de las mujeres, principales víctimas de este delito, y además supondría poner en alza la importancia de su consentimiento libre, reafirmándolas como sujeto y dándole a su libertad sexual la consideración que merece, que es el bien jurídico que se tutela. En definitiva, la necesidad de atender a las demandas sociales actuales y cumplir con las recomendaciones y acuerdos internacionales desemboca en la calificación unitaria de violación para todas las relaciones sexuales no consentidas libremente, alcanzadas por distintos medios comisivos. 
7. Se ha observado que, aunque la redacción de la ley no discrimine explícitamente entre ambos sexos y aparezca, por tanto, como igualitaria, las diferentes motivaciones jurídicas proporcionadas por jueces y magistrados en sus resoluciones pueden dar la vuelta a esta situación y resultar en una jurisprudencia que no lo es tanto. De este modo, se infiere que en el enjuiciamiento del delito de violación se precisa, en la búsqueda de igualdad real, además de la revisión legislativa, y de manera igualmente urgente y trascendental, la incorporación de una formación en perspectiva de género dirigida a los aplicadores del Derecho. Así, a la hora de apreciar las circunstancias subjetivas y personales de la víctima en cada caso concreto, que se analizan según el punto de vista de un observador neutral, conviene en ciertos casos incluir dicha perspectiva, entender que el contexto social no es el mismo para hombres y para mujeres, lo que puede hacer que estas últimas perciban como aterradoras ciertas situaciones.

\section{VI.FUENTES}

\section{Bibliografia}

ACale Sanchez, María. «Ser o no ser (de La Manada): esta es la cuestión». Nueva Tribuna, 2018, disponible en https://www.nuevatribuna.es/articulo/sociedad/serser-manada-es-cuestion/20180428190127151339.html (última consulta el 25 de junio de 2019)

— «Tratamiento penal de la violencia sexual, la forma más primaria de violencia de género». En Faraldo Cabana, Patricia y Acale Sánchez, María (Dirs.). La Manada. Un antes y un después en la regulación de los delitos sexuales en Espa$\tilde{n} a$. Valencia: Ed. Tirant lo Blanch, 2018, p. $71-90$.

Asua Batarrita, Adela. «Las agresiones sexuales en el nuevo Código Penal: imágenes culturales y discurso jurídico». En Rincón, Ana (Coord.). Análisis del código penal desde la perspectiva de género. Vitoria-Gazteiz: Emakunde-Instituto Vasco de la Mujer, 1998, p. 47-101.

Bodelón, Encarna. Violencia de género y las respuestas de los sistemas penales. Buenos Aires: Didot, 2012.

- «Cuestionamiento de la eficacia del Derecho penal en relación a la protección de los intereses de las mujeres». En RINCÓN, Ana (Coord.). Análisis del Código penal desde la perspectiva de género. Vitoria-Gazteiz: Emakunde-Instituto Vasco de la Mujer, 1998, p. 183 - 203

Boix Reig, Javier y Orts Berenguer, Enrique. «Consideraciones sobre la reforma de los delitos contra la libertad sexual, por la Ley Orgánica 11/1999» en Quintero Olivares, G. y Morales Prats, F. (Coords.). El nuevo Derecho Penal español. Navarra: Ed. Cizur Menor, 2001, p. 1007 - 1032. 
Bou Franch, Valentín. «Crímenes sexuales en la jurisprudencia internacional». Revista electrónica de Estudios Internacionales, № 24, Universidad de Valencia, 2012, p. $1-46$.

Brownmiller, Susan. Contra nuestra voluntad: hombres, mujeres y violación. Barcelona: Ed. Planeta, 1981.

Cadena Serrano, Fidel Ángel. «Tipos agravados en los delitos de agresión sexual del artículo $178 \mathrm{CP}$ y del artículo 179 CP problemas de autoría, participación, comisión por omisión y concursos en el delito de Violación». Cursos de formación del Ministerio Fiscal, 2014 disponible en https://www.fiscal.es/fiscal/PA WebApp_SGNTJ_NFIS/descarga/Ponencia_Fidel\%20Angel\%20Cadena $\% 2 \overline{0}$ Serrano.pdf?idFile=e78ac331-d98e-4509-b018-6fea52ae7c87 (última consulta el 25 de junio de 2019)

Caruso Fontán, María Viviana. Nuevas perspectivas sobre los delitos contra la libertad sexual. Valencia: Ed. Tirant lo Blanch, 2006

Cuello Calón, Eugenio. Derecho penal. Tomo II. Parte especial, Barcelona: Ed. Bosch, 1949

Cuerda Arnau, María Luisa. «Agresión y abuso sexual: Violencia o intimidación vs. Consentimiento viciado». En Faraldo Cabana, P. y Acale Sánchez, M. (Dirs.). La manada. Un antes y un después en la regulación de los delitos sexuales en España. Valencia: Ed. Tirant lo Blanch, 2018, p.103 - 131

Cugat, Miriam. «La ambivalencia de la protección de la libertad sexual. Jurisprudencia del TS sobre el delito de violación». Jueces para la democracia, $\mathrm{N}^{\mathrm{0}} 20$, 1993, p. 73-83

De Miguel, Ana. Neoliberalismo sexual: el mito de la libre elección. Undécima edición. Valencia: Ed. Cátedra, 2017.

De Vicente Martínez, Rosario. «El delito de violación: problemas que plantea su vigente redacción». En Faraldo Cabana, P. y Acale Sánchez, M. (Dirs.). La Manada. Un antes y un después en la regulación de los delitos sexuales en España. Valencia: Ed. Tirant lo Blanch, 2018, p. 171 - 214

DíEz RiPollés, José Luis. «El «No es no». El País. 2018, disponible en https://elpais. com/elpais/2018/05/03/opinion/1525363530_373340.html (última consulta el 25 de junio de 2019)

Faraldo Cabana, Patricia. «Evolución del delito de violación en los códigos penales españoles. Valoraciones doctrinales». En Faraldo Cabana, P. y Acale SÁnchez, M. (Dirs.). La manada. Un antes y un después en la regulación de los delitos sexuales en España. Valencia: Ed. Tirant lo Blanch, 2018, p. 31 - 65

— « ¿Intimidación o prevalimiento? La sentencia de La Manada y los delitos sexuales en España». Criminal Justice Network, 2018 disponible en http://www. criminaljusticenetwork.eu/es/post/intimidacion-o-prevalimiento-la-sentenciade-la-manada-y-los-delitos-sexuales-en-espana (última consulta el 25 de junio de 2019)

— y RAMON RiBAs, Eduardo. «La sentencia de La Manada y la reforma de los delitos de agresiones y abusos sexuales en España». En FAraldo Cabana, P. y ACALE SÁnchez, M. (Dirs.). La manada. Un antes y un después en la regulación de los delitos sexuales en España. Valencia: Ed. Tirant lo Blanch, 2018, p. 247 -295 . 
«Las relaciones sexuales son espontáneas y nadie quiere regularlas». El Ideal Gallego, 2018 disponible en https://www.elidealgallego.com/articulo/coruna/patriciafaraldo-relaciones-sexuales-son-espontaneas-nadie-quiere-regularlas/20180713220853378486.html (última consulta el 25 de junio de 2019)

FERNÁNDEZ, Jackeline. La violencia sexual en el derecho internacional humanitario y el estatuto de Roma. Amnistía Internacional, 2018. Disponible en https://www. amnistia.org/ve/blog/2018/03/5160/la-violencia-sexual-en-el-dih-y-el-estatutode-roma (última consulta el 25 de junio de 2019)

GAvilán RuBio, María. «Agresión sexual y abuso con prevalimiento: análisis de la reciente jurisprudencia». Revista de Derecho, Empresa y Sociedad, No 12, 2018, p. 82 - 95

Goenaga Olaizola, Reyes. «Delitos contra la libertad sexual en Estudios sobre el nuevo código penal español», 1995. Eguzkilore, Cuaderno del instituto vasco de criminología. No 10 extraordinario, 1997, p. $95-120$.

Koenig, K. Alexa, Lincoln, Ryan y Groth, Lauren. «The jurisprudence of sexual violence». University of California Berkeley: Human Rights Center, 2011.

Lascurain, Juan Antonio. «Las Huellas de la Manada». Almacén de derecho, 2018, disponible en https://almacendederecho.org/las-huellas-la-manada/ (última consulta el 5 de junio de 2019)

——¿Qué es una violación?». Criminal Justice Network, 2018, disponible en http://www.criminaljusticenetwork.eu/es/post/que-es-una-violacion (última consulta el 25 de junio de 2019)

— «Bien jurídico y legitimidad de la intervención penal». Revista chilena de derecho, Vol. $22 \mathrm{~N}^{\mathrm{o}} 2$, 1995 , p. 251 - 264

Morales Prats, Fermín y García Albero, Ramón Miguel, «Título VIII. Delitos contra la libertad e indemnidad sexuales», en Comentarios al Nuevo Código Penal, Navarra: Ed. Cizur Menor, 2016, p. 1269 -1405.

Muñoz Conde, Francisco y LóPez Peregrín, Carmen. Derecho penal. Parte especial. 21 ${ }^{\mathrm{a}}$ Edición, Valencia: Ed. Tirant lo Blanch, 2017.

Muñoz Conde, Francisco. «Los delitos contra la libertad sexual». Estudios penales y criminólogos, $\mathrm{N}^{\mathrm{o}}$ 13, 1990, p. 267 - 296.

OAKLEY, Ann. Sex, Gender and Society. Londres: Ed. Routledge, 1972.

PACHECO, Joaquín Francisco. El código penal concordado y comentado. Tomo III. Madrid: 1849, disponible en http://fama2.us.es/fde/ocr/2007/codigoPenalConcordadoT2.pdf (última consulta el 25 de junio de 2019)

PosadA, Luisa. «Otro género de violencia. Reflexiones desde la teoría feminista como teoría crítica». Revista Asparkía, No 19, 2008, p. 57 - 71 disponible en https://dialnet.unirioja.es/descarga/articulo/3171182.pdf (última consulta el 25 de junio de 2019)

RAMON RIBAS, Eduardo. «La intimidación en los delitos sexuales: entre las agresiones y los abusos sexuales». En Faraldo Cabana, P. y Acale Sánchez, M. (Dirs.). La manada. Un antes y un después en la regulación de los delitos sexuales en España. Valencia: Ed. Tirant lo Blanch, 2018, p.133 - 168.

—El concepto de intimidación en los delitos de agresiones sexuales. Comentario de la STS 1396/1999, de octubre (RJ 1999,7597)». Revista de derecho y proceso penal, $\mathrm{N}^{\mathrm{o}} 10,2003$, p. $263-284$. 
SANCHez Busso, Mariana. «El sistema penal: ¿una herramienta antidiscriminatoria?». Anuario del CIJS, 2008, p. 760 - 771.

SuAY Hernandez, Blanca Celia. «Ausencia de consentimiento e intimidación en el delito de violación (Comentario a la STS de 16 de enero de 1991. El caso del «alfiler»)». La Ley, Nº1, 1992, p. 1062-1071

VAllejo TORRes, Carla. «Delitos contra la libertad sexual y perspectiva de género: una mirada hacia fuera para reflexionar desde dentro». La Ley, $\mathrm{N}^{\circ}$ 9263, 2018, p. $1-11$.

WeSt, Robin. «The Difference in Women's Hedonic Lives: A phenomenological critique of feminist legal theory». Wisconsin women's law journal, № 3, 1987, p. $149-215$.

Zorrilla, Maider. La Corte Penal Internacional ante el crimen de violencia sexual. Universidad de Deusto. Instituto de Derechos Humanos, 2005.

\section{Legislación}

Convenio sobre Prevención y Lucha contra la Violencia contra la Mujer y la Violencia doméstica, Consejo de Europa, en Estambul el 12 de abril de 2011. Ratificado por España el 10 de abril de 2014. Publicado en el BOE nº. 137, de 6 de junio de 2014, p. 42946-42976.

Protocolo Adicional a la Carta Africana sobre los Derechos Humanos y de los Pueblos, Unión Africana, en Maputo el 11 de julio de 2003.

Estatuto de Roma de la Corte Penal Internacional de Naciones Unidas, de 17 de julio de 1998, A/Conf. 183/9 que entra en vigor el 1 de julio de 2002. Instrumento de ratificación de España, Boletín Oficial del Estado, 27 de mayo de 2002, n 126, p. 18824.

Declaración y Plataforma de Acción de Pekín, de la Asamblea General de la ONU aprobada en Pekín en la $16^{\mathrm{a}}$ sesión plenaria de 15 de septiembre de 1995.

Convención Interamericana para Prevenir, Sancionar y Erradicar la Violencia contra la Mujer, de la Organización de Estados Americanos, en Belem do Pará el 9 de junio de 1994.

Declaración sobre la eliminación de violencia contra la mujer, de la Asamblea General de la ONU de 1993 adoptada en la 85ª sesión plenaria del 20 de diciembre de 1993.

Convenio de Ginebra relativo a la protección debida a las personas civiles en tiempo de guerra de la Conferencia Diplomática para Elaborar Convenios Internacionales destinados a proteger a las víctimas de la guerra, aprobado en Ginebra el 12 de agosto de 1949. Disponible en https:/www.icrc.org/es/doc/resources/documents/ treaty/treaty-gc-4-5tdkyk.htm

Convenio IV relativo a las leyes y costumbres de la guerra terrestre, firmado en La Haya el 18 de octubre de 1907 por la Partes Contratantes. Disponible en la página web del Comité Internacional de la Cruz Roja https:/www.icrc.org/es/doc/resources/documents/misc/treaty-1907-regulations-laws-customs-war-on-land5tdm39.htm

Protocolo I Adicional a los Convenios de Ginebra de 1949 relativo a la protección de las víctimas de los conflictos armados internacionales, de la Conferencia Diplo- 
mática sobre la Reafirmación y el Desarrollo del Derecho Internacional Humanitario Aplicable en los Conflictos Armados, aprobado el 8 de junio de 1977 dispon ible en ht p s:// w w w i crcorg/e s/document/ protocolo-i-adicional-convenios-ginebra-1949-proteccion-victimas-conflictosarmados-internacionales-1977 (última consulta el 25 de junio de 2019)

Protocolo II adicional a los Convenios de Ginebra de 1949 relativo a la protección de las víctimas de los conflictos armados sin carácter internacional, de la Conferencia Diplomática sobre la Reafirmación y el Desarrollo del Derecho Internacional Humanitario Aplicable en los Conflictos Armados, aprobado el 8 de junio de 1977 disponible en https://www.icrc.org/es/doc/resources/documents/misc/protocolo-ii.htm (última consulta el 25 de junio de 2019)

Resolución 955 del Consejo de Seguridad de la ONU de 8 noviembre de 1994 disponible en https://undocs.org/es/S/RES/955\%20(1994) (última consulta el 25 de junio de 2019)

Resolución 808 del Consejo de Seguridad de la ONU de 22 de febrero de 1993 disponible en https://undocs.org/es/S/RES/808\%20(1993) (última consulta el 25 de junio de 2019)

Recomendación General No 35 sobre la violencia por razón de género contra la mujer por la que se actualiza la Recomendación general $n^{\circ} 19$ del Comité CEDAW de 26 de julio de 2017.

Recomendación general $\mathrm{N}^{\mathrm{O}} 28$ relativa al artículo 2 de la Convención sobre la eliminación de todas las formas de discriminación contra la mujer, del Comité CEDAW de 16 de diciembre de 2010.

Recomendación General N ${ }^{\circ} 19$ sobre la violencia contra la mujer del Comité para la Eliminación de la Discriminación contra la Mujer, del Comité CEDAW del 29 de enero de 1992.

Control Council Law No. 10, Punishment of Persons Guilty of War Crimes, Crimes Against Peace and Against Humanity, del Official Gazette Control Council for Germany, de 20 de diciembre de 1945 disponible en https://www.legal-tools.org/ doc/ffda62/pdf/ (última consulta el 25 de junio de 2019)

Agreement for the prosecution and punishment of the major war criminals of the European Axis firmado por el Reino Unido de Gran Bretaña e Irlanda del Norte, los Estados Unidos de América, Francia y la Unión de Repúblicas Socialistas Soviéticas en Londres el 8 de agosto de 1945. Disponible en https:/www.un.org/ en/genocideprevention/documents/atrocity-crimes/Doc.2_Charter\%20of\%20 IMT\%201945.pdf (última consulta el 25 de junio de 2019)

Proyecto de texto definitivo de los Elementos de los Crímenes de la Comisión Preparatoria de la Corte Penal Internacional de 2 de noviembre del 2000, PCNICC/2000/1/Add.2.

Código Penal de Bélgica, de 8 de junio de 1867, Título VII, disponible en www. ejustice.just.fgov.be/cgi_loi/loi_a1.pl?language $=$ fr\&caller $=$ list\&cn $=186706080$ $1 \& \mathrm{la}=\mathrm{f} \&$ fromtab $=\mathrm{loi} \& \operatorname{tri}=\mathrm{dd}+\mathrm{as}+\mathrm{rank} \#$ LNKR0127 (última consulta el $25 \mathrm{de} \mathrm{ju}$ nio de 2019)

Código Penal de Países Bajos, de 3 marzo de 1881, Parte XIV, disponible en www. legislationline.org/documents/section/criminal-codes (última consulta el 25 de junio de 2019) Instructions for the Government of Armies of the United States in 
the Field (Lieber Code) de 24 de abril de 1863. Disponible en la página web del Comité Internacional de la Cruz Roja https://ihl-databases.icrc.org/ihl/INTRO/110 (última consulta el 25 de junio de 2019)

\section{Jurisprudencia}

Sentencia de la Sala de Apelaciones del Tribunal Penal Internacional para la Antigua Yugoslavia de 12 de junio de 2002, The prosecutor v. Dragoljub Kunarac, Radomir Kovac y Zoran Vukovic, n ${ }^{\circ}$ IT-96-23 \& IT-96-23/1-A disponible en http:// www.icty.org/x/cases/kunarac/acjug/en/kun-aj020612e.pdf (última consulta el 25 de junio de 2019)

Sentencia del Tribunal Penal Internacional para la Antigua Yugoslavia de 22 de febrero de 2001, The prosecutor v. Dragoljub Kunarac, Radomir Kovac y Zoran Vukovic. No IT-96-23-T\& IT-96-23/1-A disponible en http://www.icty.org/x/ cases/kunarac/tjug/en/kun-tj010222e.pdf (última consulta el 25 de junio de 2019)

Sentencia del Tribunal Penal Internacional para la Antigua Yugoslavia de 10 de diciembre de 1998, The Prosecutor v. Anto Furundzija, n IT-95-17/1-T disponible en http://www.icty.org/x/cases/furundzija/tjug/en/fur-tj981210e.htm (última consulta el 25 de junio de 2019)

Sentencia del Tribunal Penal Internacional para Ruanda de 27 de enero del 2000. The prosecutor v. Alfred Musema, no ICTR-96-13-A disponible en https://www.legal-tools.org/doc/1fc6ed/pdf/ (última consulta el 25 de junio de 2019)

Sentencia del Tribunal Penal Internacional para Ruanda de 2 de septiembre de 1998, The Prosecutor v. Jean-Paul Akayesu, ICTR-96-4-A-T en http://www.worldcourts.com/ictr/eng/decisions/1998.09.02_Prosecutor_v_Akayesu.pdf (última consulta el 25 de junio de 2019)

Sentencia del Tribunal Europeo de Derechos Humanos. E.B v Romania Application $n^{\circ} .49089 / 10$ de 19 de marzo de 2019.

Sentencia del Tribunal Europeo de Derechos Humanos. M.C. v Bulgaria, n ${ }^{\circ}$. 39279/98, ECHR 2203XII de 4 de diciembre de 2003.

Sentencia de la Corte Interamericana de Derechos Humanos. González y otras («Campo algodonero») v México de 16 de noviembre de 2009

Dictamen del Comité CEDAW. Karen Tayag Vertido v Filipinas, Comunicación núm. 18/2008, CEDAW/C/46/D/18/2008 de 22 de septiembre de 2010.

STS no. 914/2018, de 22 de diciembre de 2018

STS no. 724/2018, de 24 de enero de 2018

STS no. 786/2017, de 30 de noviembre de 2017

STS no. 573/2017, de 18 de julio de 2017

STS no. 460/2017, de 21 de junio de 2017

STS no. 630/2016, de 14 de julio de 2016

STS n ${ }^{\circ} .216 / 2016$ de 24 de abril de 2016

STS n ${ }^{\circ}$. 132/2016, de 23 de febrero de 2016

STS n ${ }^{\circ} .9 / 2016$, de 21 de enero de 2016

STS no. 769/2015, de 15 de Diciembre de 2015

STS no. 355/2015, 28 de mayo de 2015 
STS n'. 834/2014, de 10 de diciembre de 2014

STS no. 553/2014, de 30 de junio de 2014

STS n ${ }^{\circ}$. 102/2014, de 18 de febrero de 2014

STS no. 609/2013, de 10 de julio de 2013

STS no. 512/2013, de 13 de junio de 2013

STS no. 542/2013, de 20 de mayo de 2012

STS no. 305/2013, de 12 de abril de 2013

STS n ${ }^{\circ} .203 / 2013$, de 7 de marzo de 2013

STS no. 1030/2010, de 2 de Diciembre de 2010

ATS n ${ }^{\circ} .2333 / 2009$, de 13 octubre de 2009

STS no. 914/2008, de 22 de diciembre de 2008

STS no. 6095/2008, de 5 de noviembre de 2008

STS n ${ }^{\circ} .511 / 2007$, de 7 de junio de 2007

STS n'. 935/2006, de 2 de Octubre de 2006

STS n ${ }^{\circ} .1291 / 2005$, de 8 de noviembre de 2005

STS $n^{\circ} .744 / 2004$, de 14 junio de 2004

STS n ${ }^{\circ} .578 / 2004$, de 26 de abril de 2004

STS no. 413/2004 de 31 de marzo de 2004

STS no. 1689/2003, de 18 de diciembre de 2003

STS no. 919/2003, de 19 de junio de 2003

STS no. 593/2003, de 16 de abril de 2003

STS no. 1458/2002, de 17 de septiembre de 2002

STS no. 1875/2002, de 14 de febrero de 2003

STS no. 1714/2001, de 2 de octubre de 2001

STS n ${ }^{\circ}$ rec. 3083/1999, de 10 de julio de 2001

STS no. 937/2000 de 26 de mayo de 2000

STS n ${ }^{\circ} .1366 / 1999$, de 1 de octubre de 1999

STS n ${ }^{\circ}$ rec. 507/1996, de 3 de octubre de 1997

STS n ${ }^{\circ}$ Rec. 687/1991, de 8 de febrero de 1991

STSJ de Navarra ${ }^{\circ}$. 38/2018, de 30 de noviembre de 2018

SAP de Navarra, no. 38/2018, de 20 de marzo de 2018

\section{Otros documentos}

Agencia de los Derechos Fundamentales de la UE. Violence Against Women: an EU-wide survey. Main Results. Luxemburgo: 2014. Disponible en https://fra. europa.eu/sites/default/files/fra_uploads/fra-2014-vaw-survey-main-resultsapr14_en.pdf (última consulta el $\overline{2} 5$ de junio de 2019)

AMnistía InTERNACIONAL. Right to be free from rape. Overview of legislation and state of play in Europe and international human right standards. 2018, disponible en https://www.amnesty.org/en/documents/eur01/9452/2018/en (última consulta el 25 de junio de 2019)

CONSEJo DE EuRopa. Explanatory Report to the Council of Europe Convention on preventing and combating violence against women and domestic violence Istanbul, Estambul, 2011. 
EQuality Now. The world's shame. The Global Rape Epidemic. How laws around the world are failing to protect women and girls from sexual violence, 2017, disponible en https://www.equalitynow.org/the_world_s_shame_the_global_rape epidemic_how_laws_around_the_world_are_failing_to_protect_women_and_ girls_from_sexual_violence (última consulta êl 25 de junio de 2019)

Grupo Parlamentario Confederal de Unidos Podemos-En Comú Podem-En Marea. Proposición de Ley de Protección Integral de la Libertad Sexual y para la erradicación de las violencias sexuales. Boletín Oficial de las Cortes Generales. Congreso de los Diputados. XII Legislatura. Serie B: Proposiciones de Ley, núm. 297-1, de 20 de julio de 2018

MINISTERIO DE INTERIOR. Informe sobre delitos contra la libertad e indemnidad sexual en España. Gabinete de Coordinación y Estudios, Secretaría de Estado de Seguridad, 2017. Disponible en http://www.interior.gob.es/documents/10180/0/Informe+ delitos+contra+la+libertad+e+indemnidad+sexual+2017.pdf/da546c6c-36c54854-864b-a133f31b4dde (última consulta el 25 de junio de 2019)

MINISTERIO DE INTERIOR. Infracciones penales registradas en CCAAs, provincias, islas, capitales y localidades con población superior a 30.000 habitantes. Gabinete de Coordinación y Estudios, Secretaría de Estado de Seguridad, 2018. disponible en http://www.interior.gob.es/documents/10180/8736571/ informe+balance $+2018+4 \% \mathrm{C} 2 \% \mathrm{BA} \% 20$ trimestre.pdf/fb51653e-77f5-44da9d23-535dbf4b2edd (última consulta el 25 de junio de 2019)

NACIONES UnidAS. Handbook for Legislation on Violence against Women. United Nations Entity for Gender Equality and the Empowerment of Women, 2010, p. 24 disponible en http://www.unwomen.org/en/digital-library/publications/2012/12/handbook-for-legislation-on-violence-against-women (última consulta el 25 de junio de 2019)

NACIONES Unidas. The Special Rapporteur on Violence against Women, 15 years of the United Nations Special Rapporteur on Violence Against Women, Its Causes and Consequences. 2009. Disponible en https://www.ohchr.org/Documents/Issues/Women/15YearReviewofVAWMandate.pdf (última consulta el 25 de junio de 2019)

Oficina del Alto Comisionado de las Naciones Unidas para los Derechos Humanos. Los derechos de la mujer son derechos humanos, 2014. Disponible en https://www.ohchr.org/Documents/Publications/HR-PUB-14-2_SP.pdf (última consulta el 25 de junio de 2019)

Organización Mundial DE LA SALud. Informe mundial sobre la violencia y la salud, Washington, D.C.: Oficina Regional para las Américas de la Organización Mundial de la Salud, 2003.

Salud Mental Te Cree. Carta abierta de los/as profesionales de la psicología y la psiquiatría al Ministerio de Justicia y a la ciudadanía, 2018 disponible en http:// comunicadosaludmental.blogspot.de/2018/05/carta-abierta-de-losas-profesionales-de.html (última consulta el 25 de junio de 2019)

Tribunal Supremo. Comunicado sobre el fallo del TS No Rec. 396/2019, de 21 de junio disponible en http://www.poderjudicial.es/cgpj/es/Poder-Judicial/NoticiasJudiciales/Comunicado-de-la-Sala-Segunda-del-Tribunal-Supremo-sobre-el-recurso-de-casacion-396-2019 (última consulta el 25 de junio de 2019) 
UNICEF. A familiar face: violence in the life of children and adolescents. Nueva York: 2017. Disponible en https://www.unicef.org/publications/files/Violence in_the_lives_of_children_and_adolescents.pdf (última consulta el 25 de junio de 2019)

\section{ANEXOS}

\section{ANEXO I}

Gráfico que muestra el número de hechos conocidos de agresión sexual y abuso sexual con penetración en España desde 2012 hasta 2017:

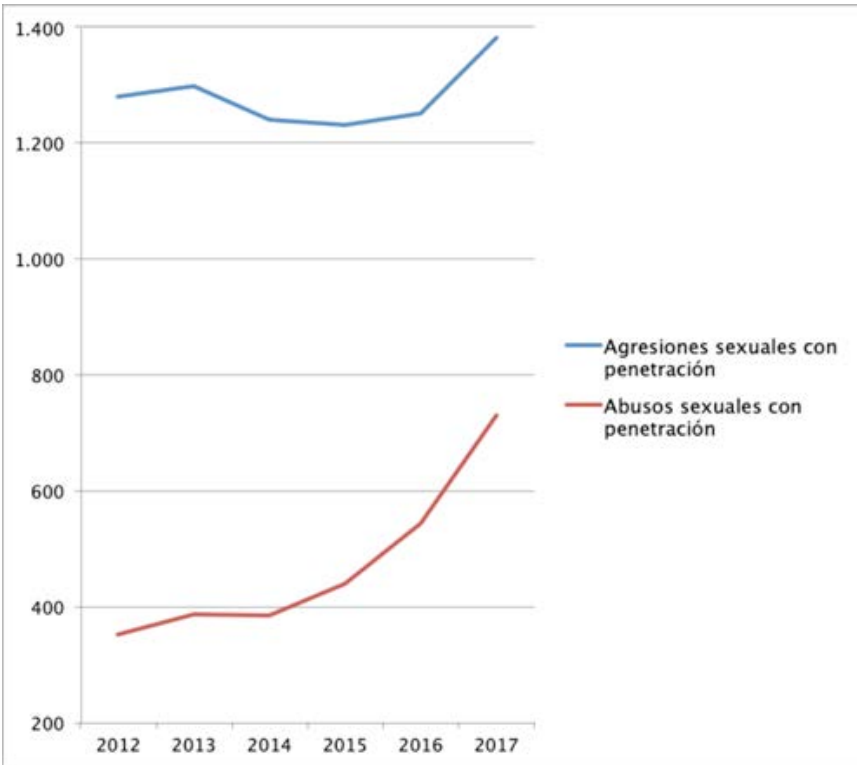

Elaboración propia.

Fuente: Datos España delitos contra la libertad sexual. Ministerio de Interior, 2017, p. 7 disponible en http://www.interior.gob.es/documents/10180/0/Info rme+delitos + contra+la+libertad $+e+$ indemnidad + sexual $+2017 . p d f /$ da546c6c-36c5-4854-864b-a133f31b4dde (última consulta el 25 de junio de 2019)

\section{ANEXO II}

Tabla comparativa de los tres tratados internacionales de los sistemas regionales de protección y promoción de los derechos humanos que regulan 
la violencia contra la mujer (por motivos de espacio, se trata de un resumen de sus disposiciones):

\begin{tabular}{|c|c|c|c|}
\hline & $\begin{array}{c}\text { Convención } \\
\text { Interamericana para } \\
\text { Prevenir, Sancionar y } \\
\text { Erradicar la Violencia } \\
\text { contra la Mujer } \\
\text { (Convención Belem do } \\
\text { Pará) }\end{array}$ & $\begin{array}{c}\text { Protocolo Adicional } \\
\text { a la Carta Africana } \\
\text { sobre los Derechos } \\
\text { Humanos y de los } \\
\text { Pueblos (Protocolo } \\
\text { de Maputo) }\end{array}$ & $\begin{array}{l}\text { Convenio sobre } \\
\text { Prevención y Lucha } \\
\text { contra la Violencia } \\
\text { contra la Mujer y la } \\
\text { Violencia doméstica } \\
\text { (Convenio de Estambul) }\end{array}$ \\
\hline Fecha & 1994 & 2003 & 2011 \\
\hline Definición & $\begin{array}{l}\text { - Física, sexual y } \\
\text { psicológica } \\
\text { - Ámbito público y } \\
\text { privado } \\
\text { - Basados en el género }\end{array}$ & $\begin{array}{l}\text { - Física, sexual y } \\
\text { psicológica } \\
\text { - Ámbito público y } \\
\text { privado } \\
\text { - Violencia } \\
\text { económica } \\
\text { - Amenazas } \\
\text { - Privación } \\
\text { arbitraria de } \\
\text { libertad }\end{array}$ & $\begin{array}{l}\text { - Física, sexual y } \\
\text { psicológica } \\
\text { - Ámbito público y } \\
\text { privado } \\
\text { - Violencia económica } \\
\text { - Amenazas } \\
\text { - Privación arbitraria de } \\
\text { libertad } \\
\text { - Basados en el género }\end{array}$ \\
\hline $\begin{array}{l}\text { Ámbito de } \\
\text { aplicación }\end{array}$ & $\begin{array}{l}\text { - Violación, maltrato y } \\
\text { abuso sexual, tortura, } \\
\text { trata de personas, } \\
\text { prostitución forzada, } \\
\text { secuestro y acoso } \\
\text { sexual } \\
\text { - Ámbito doméstico } \\
\text { (siempre que se } \\
\text { «comparta o haya } \\
\text { compartido } \\
\text { domicilio») } \\
\text { - Instituciones } \\
\text { educativas, lugar de } \\
\text { trabajo y } \\
\text { establecimientos de } \\
\text { salud } \\
\text { - Conflictos armados }\end{array}$ & $\begin{array}{l}\text { Además de las } \\
\text { anteriores, } \\
\text { novedades: } \\
\text { - Experimentos sin } \\
\text { consentimiento, } \\
\text { MGF, } \\
\text { escarificación, } \\
\text { matrimonios } \\
\text { forzosos } \\
\text { - Instituciones } \\
\text { educativas } \\
\text { - Conflictos } \\
\text { armados } \\
\text { - Incluye a la niñas }\end{array}$ & $\begin{array}{l}\text { Además de todas las } \\
\text { anteriores, novedades: } \\
\text { - Crímenes en nombre } \\
\text { del honor, violencia } \\
\text { sexual sistémica, } \\
\text { aborto y esterilización } \\
\text { forzosos } \\
\text { - Ámbito doméstico } \\
\text { («independientemente } \\
\text { de que se comparta o } \\
\text { haya compartido } \\
\text { domicilio») } \\
\text { - Conflictos armados } \\
\text { - Incluye a las niñas }\end{array}$ \\
\hline
\end{tabular}




\begin{tabular}{|c|c|c|c|}
\hline $\begin{array}{l}\text { Obligaciones } \\
\text { estatales }\end{array}$ & $\begin{array}{l}\text { - Prevención, sanción y } \\
\text { erradicación: adoptar } \\
\text { políticas, actuar con } \\
\text { debida diligencia e } \\
\text { incluir legislación } \\
\text { - Evaluación de } \\
\text { medidas: recopilación } \\
\text { de datos que se } \\
\text { pondrá a disposición } \\
\text { de expertos } \\
\text { - Reparación de daños } \\
\text { a las víctimas } \\
\text { - Protección de las } \\
\text { víctimas: servicios y } \\
\text { programas necesarios, } \\
\text { refugios, cuidado de } \\
\text { menores } \\
\text { - Procedimientos } \\
\text { legales justos y } \\
\text { eficaces, juicio } \\
\text { oportuno } \\
\text { - Especial } \\
\text { consideración en } \\
\text { posibles situaciones } \\
\text { de vulnerabilidad }\end{array}$ & $\begin{array}{l}\text { - Prevención, } \\
\text { sanción y } \\
\text { erradicación: } \\
\text { adoptar políticas, } \\
\text { actuar con debida } \\
\text { diligencia e incluir } \\
\text { legislación } \\
\text { - Reparación de } \\
\text { daños a las } \\
\text { víctimas } \\
\text { - Protección de las } \\
\text { víctimas: } \\
\text { rehabilitación, } \\
\text { necesidad de } \\
\text { apoyo en } \\
\text { conflictos, } \\
\text { escuelas y en } \\
\text { cuanto a prácticas } \\
\text { dañinas } \\
\text { - Igualitario acceso } \\
\text { a la justicia y } \\
\text { órganos legales } \\
\text { igualitarios } \\
\text { - Especial } \\
\text { consideración a } \\
\text { mujeres ancianas, } \\
\text { con } \\
\text { discapacidades, } \\
\text { embarazadas o en } \\
\text { periodo de } \\
\text { lactancia y en } \\
\text { prisión }\end{array}$ & $\begin{array}{l}\text { - Prevención, sanción y } \\
\text { erradicación: } \\
\text { sensibilización, } \\
\text { formación de } \\
\text { profesionales, } \\
\text { programas } \\
\text { preventivos de } \\
\text { intervención y } \\
\text { tratamiento, } \\
\text { participación del } \\
\text { sector privado } \\
\text { - Evaluación de } \\
\text { medidas: recopilación } \\
\text { de datos que se pondrá } \\
\text { a disposición de } \\
\text { expertos y el público } \\
\text { en general } \\
\text { - Reparación de daños a } \\
\text { través de } \\
\text { indemnización } \\
\text { - Protección de las } \\
\text { víctimas: medidas de } \\
\text { protección ante } \\
\text { nuevos episodios, } \\
\text { servicios jurídicos, } \\
\text { psicológicos, de } \\
\text { alojamiento, búsqueda } \\
\text { de empleo, } \\
\text { información sobre las } \\
\text { demandas aplicables, } \\
\text { casas de acogida, } \\
\text { guardias telefónicas, } \\
\text { etc. } \\
\text { - Procedimientos } \\
\text { legales que cumplan } \\
\text { una amplia lista de } \\
\text { requisitos: sin } \\
\text { demoras } \\
\text { injustificadas, } \\
\text { respuestas rápidas y } \\
\text { eficaces de los } \\
\text { cuerpos de seguridad, } \\
\text { asistencia legal } \\
\text { gratuita, etc. }\end{array}$ \\
\hline
\end{tabular}




\begin{tabular}{|c|c|c|c|}
\hline $\begin{array}{l}\text { Factor } \\
\text { sociocultural }\end{array}$ & $\begin{array}{l}\text { - Importancia de } \\
\text { modificar patrones } \\
\text { socioculturales que } \\
\text { promuevan } \\
\text { costumbres y } \\
\text { estereotipos de } \\
\text { inferioridad de la } \\
\text { mujer. } \\
\text { - Manifestación de } \\
\text { relaciones históricas } \\
\text { desiguales } \\
\text { - Carácter transversal } \\
\text { - Importancia de la } \\
\text { educación } \\
\text { - Medios de } \\
\text { comunicación }\end{array}$ & $\begin{array}{l}\text { - Importancia de } \\
\text { modificar patrones } \\
\text { socioculturales que } \\
\text { promuevan } \\
\text { costumbres y } \\
\text { estereotipos de } \\
\text { inferioridad de la } \\
\text { mujer. } \\
\text { - Importancia de la } \\
\text { educación } \\
\text { - Medios de } \\
\text { comunicación }\end{array}$ & $\begin{array}{l}\text { - Importancia de } \\
\text { modificar patrones } \\
\text { socioculturales que } \\
\text { promuevan } \\
\text { costumbres y } \\
\text { estereotipos de } \\
\text { inferioridad de la } \\
\text { mujer. } \\
\text { - Manifestación de } \\
\text { relaciones históricas } \\
\text { desiguales } \\
\text { - Carácter estructural } \\
\text { - Mecanismo de } \\
\text { subordinación de } \\
\text { mujeres } \\
\text { - Importancia de la } \\
\text { educación } \\
\text { - Medios de } \\
\text { comunicación } \\
\text { - Sector privado y } \\
\text { tecnología }\end{array}$ \\
\hline
\end{tabular}

Elaboración propia. Fuentes:

- Convenio sobre Prevención y Lucha contra la Violencia contra la Mujer y la Violencia doméstica, Consejo de Europa, en Estambul el 12 de abril de 2011. Ratificado por España el 10 de abril de 2014. Publicado en el BOE $\mathrm{n}^{\mathrm{o}} .137$, de 6 de junio de 2014, p. 42946-42976.

- Protocolo Adicional a la Carta Africana sobre los Derechos Humanos y de los Pueblos, Unión Africana, en Maputo el 11 de julio de 2003.

- Convención Interamericana para Prevenir, Sancionar y Erradicar la Violencia contra la Mujer, la Organización de Estados Americanos, en Belem do Pará el 9 de junio de 1994. 


\title{
EL DELITO DE VIOLACIÓN EN EL CÓDIGO PENAL ESPAÑOL: ANÁLISIS DE LA DIFÍCIL DELIMITACIÓN ENTRE LA INTIMIDACIÓN DE LA AGRESIÓN SEXUAL Y EL PREVALIMIENTO DEL ABUSO SEXUAL. REVISIÓN A LA LUZ DE LA NORMATIVA INTERNACIONAL
}

The crime of rape in the Spanish Criminal Code: analysis of the difficult delimitation between intimidation of sexual assault and "prevalimiento» of sexual abuse. A revision in the light of the international regulations

\author{
Itziar Altuzarra Alonso \\ Universidad de Deusto \\ itziar.altuzarra@opendeusto.es
}

http://dx.doi.org/10.18543/ed-68(1)-2020pp511-558

\section{Copyright}

Estudios de Deusto es una revista de acceso abierto, lo que significa que es de libre acceso en su integridad. Se permite su lectura, la búsqueda, descarga, distribución y reutilización legal en cualquier tipo de soporte sólo para fines no comerciales, sin la previa autorización del editor o el autor, siempre que la obra original sea debidamente citada y cualquier cambio en el original esté claramente indicado

Estudios de Deusto is an Open Access journal which means that it is free for full access, reading, search, download, distribution, and lawful reuse in any medium only for non-commercial purposes, without prior permission from the Publisher or the author; provided the original work is properly cited and any changes to the original are clearly indicated. 